\title{
The Ethiopic Jannes and Jambres and the Greek Original
}

\author{
Ted M. Erho \& W. Benjamin Henry*
}

\begin{abstract}
Publication of a fragment of Jannes and Jambres in Ge'ez, together with new editions of relevant parts of the Greek papyri and observations on the reconstruction of the book.
\end{abstract}

Keywords: Chester Beatty papyri, Ethiopic manuscripts, Hellenistic Judaism, Jannes and Jambres, Old Testament pseudepigrapha

https://doi.org/10.1515/apf-2019-0010

A recently identified fragment of an Ethiopic translation of the Old Testament apocryphon of Jannes and Jambres sheds much new light on the book, of which we are preparing a complete integrated edition with English translation. We present below (I) the editio princeps of the Ethiopic text and (II) revised editions of related parts of the Greek, including several new joins, followed by a brief account of the structure of the work in the light of the evidence now available.

The following abbreviations may be noted:

Vorbemerkung: Erho is responsible for section I, and Henry for section II. However, both parts have been greatly enhanced by a mutually illuminating correspondence over several years, and in a number of cases the results are the product of ideas that have been reshaped and refined several times by both scholars. The authors would like to thank Albert Pietersma for facilitating early discussions on the Greek apocryphon in the light of the Ethiopic fragment and putting them in touch with one another. Erho would additionally like to thank Getatchew Haile, who read some early drafts of the edition and translation of the Ethiopic text, and the appointed reviewer of the Ethiopic section, both of whom made several helpful suggestions which have been incorporated.

*Kontakt: T.M. Erho, Ludwig-Maximilians-Universität München, Evangelisch-Theologische Fakultät, Geschwister-Scholl-Platz 1,80539 München, Germany, <Ted.Erho@ev theol.uni-muenchen.de>; W.B. Henry, Department of Greek and Latin, University College London, Gower Street, London WC1E 6BT, United Kingdom, <w.henry@ucl.ac.uk> 
T.M. Erho \& W.B. Henry, The Ethiopic Jannes \& Jambres \& the Greek Original 177

\section{Books and Articles}

Henry W.B. Henry, Notes on Jannes and Jambres (P.Chester Beatty XVI), ZPE 198 (2016) 59-67.

Hirschberger M. Hirschberger, Die Magier des Pharao - Das Buch der Worte von Jannes und Jambres in seinem Kontext, in ead. (ed.), Jüdisch-hellenistische Literatur in ihrem interkulturellen Kontext (2012) 213-65.

Maraval P. Maraval, Fragments grecs du Livre de Jannès et Jambré (Pap.Vindob. 29456 et 29828 Verso), ZPE 25 (1977) 199-207.

Oellacher H. Oellacher, Papyrus- und Pergamentfragmente aus Wiener und Münchner Beständen, in Miscellanea Giovanni Galbiati II (Fontes Ambrosiani 26; 1951) 179-88.

Pietersma A. Pietersma, The Apocryphon of Jannes and Jambres the Magicians: P.Chester Beatty XVI (with New Editions of Papyrus Vindobonensis Greek inv. $29456+29828$ verso and British Library Cotton Tiberius B. $v$ f. 87) (RGRW 119; 1994).

Pietersma, A. Pietersma, Two More Fragments of the Vienna Jannes and Jambres, Fragments BASP 49 (2012) 21-9.

Schmelz G. Schmelz, Zwei neue Fragmente des Apokryphons über die Zauberer Jannes und Jambres, Pap. Congr. XXII (2001) 1199-1212.

\section{Manuscripts}

B

P.Chester Beatty CBL BP XVI, 4th century (MP³ 2640.1, LDAB 5622).

Edition: Pietersma with pls. 1-16; Hirschberger 230-65.

Online images: http://csntm.org/Manuscript/View/BP_XVI; https://viewer. cbl.ie.

Eth The Ethiopic fragment, Schneider ms. frag. 19, edited in $\S$ I below.

H P.Heid. inv. G 1016, 4th century (MP ${ }^{3}$ 2640.31, LDAB 8898).

Edition: Schmelz 1207-12 with pl. XLVI; Hirschberger 244-5.

Online images: http://digi.ub.uni-heidelberg.de/diglit/p_g_1016.

$\mathrm{O}$

P.Oxy. LXXXII 5290, 4th century (MP ${ }^{3}$ 2640.32, LDAB 702420).

Images: ed.pr. (pl. I).

P.Vindob. G $29456+29828+180+28249$ v., 3rd century $\left(\mathrm{MP}^{3} 2640.2\right.$, LDAB 5467).

Editions: Oellacher 185-7; Maraval 201-3; Pietersma 268-9, 272-3; Hirschberger 236-43, 256-7; Pietersma, Fragments 23-4 (fr. A). The lines of fr. A are numbered as in Pietersma, Fragments, which includes the first edition of the first six lines of the column.

Printed images: Pietersma pl. 17 (lacking the top of fr. A); Pietersma, Fragments 29 (fr. A complete).

Online images: http://data.onb.ac.at/rep/1020EA29. 


\section{The Ethiopic fragment}

Several years ago M.-L. Derat signalled the existence of a small set of Ethiopian manuscript fragments, collected as palaeographic study samples, in R. Schneider's Nachlass, posthumously deposited at the Walda Masqal Centre of the Institute of Ethiopian Studies in Addis Ababa. ${ }^{1}$ One of the fragments, now provisionally assigned the siglum 'Schneider ms. frag. 19', consists of part of a hitherto unknown Ge'ez (Classical Ethiopic) translation of the Greek Apocryphon of Jannes and Jambres. Unlike most of its counterparts, which various pieces of information link to Gunda Gundē or $\mathrm{G}^{\mathrm{w}} \mathrm{e}$, ${ }^{2}$ its provenance cannot be established.

Schneider ms. frag. 19 comprises a parchment bifolium of non-consecutive leaves measuring $29.5 \times 21.8 \mathrm{~cm}$ when closed. Though generally well preserved, its upper inside corner has suffered damage of an undetermined nature, resulting in the loss of a few letters on each page. The flesh side of the parchment lies inside and the hair side to the outside; the former is much easier to read than the latter, on which letters have become obscured in places to varying degrees. Its location in its original quire cannot be readily established: both the outermost and second outermost sheets of a quaternion are possible positions, with the former preferable based upon an estimation of intervening text found in B and the latter if early Ethiopian codices were assembled in a fashion similar to Greek parchment codices and followed Gregory's rule. ${ }^{3}$ It is laid out in the customary twocolumn format, with twenty-two lines on both recto and verso of the first leaf, and twenty-one on the second. Unusually, virtually no punctuation is included apart from word dividers, and marginal sigla and paragraphing are completely lacking. On the second leaf, the scribe has written around a significant flaw in the parchment; elsewhere, lines average nine letters each. Only numerals are rubricated. ${ }^{4}$

\footnotetext{
${ }^{1}$ M.-L. Derat, Les archives Roger Schneider (1917-2002) au centre Walda Masqal (Institute of Ethiopian Studies, Addis Abeba), Annales d'Éthiopie 26 (2011) 291-302 (at $297,300)$. It was on the basis of digital images of the fragment under discussion kindly shared by M.-L. Derat that its contents were first identified in October 2014. A catalogue describing all of the fragments in this collection is in preparation.

${ }^{2}$ For the locations of these ecclesiastical institutions in the Tigray Region of north Ethiopia, see the maps in S. Uhlig (ed.), Encyclopaedia Aethiopica ii (2005) 699 and 918.

${ }^{3}$ Cf. E.G. Turner, The Typology of the Early Codex (1977) 56.

${ }^{4}$ Interestingly, the formatting of the numerals is not consistent. The first two, at the top of f. $2 r^{a}$, both exhibit rubricated lines above and below the numbers, a feature unattested in any of the subsequent cases. In f. $2 \mathrm{r}^{\mathrm{a}} 3$, the rubricator also adds an additional word divider
} 
Given the shifting and very incomplete state of our present knowledge of early Ethiopian manuscript palaeography, ${ }^{5}$ it is difficult to assign a firm date to this fragment. Nevertheless, certain characteristics, most notably the completely discrete strokes added onto the base forms of letters to indicate vowel orders, e.g. $\boldsymbol{\Lambda}$ to $\boldsymbol{\Lambda}, \boldsymbol{\Omega}$ to $\mathbf{\Omega}, \boldsymbol{\sigma D}$ to $\boldsymbol{\Phi}, \boldsymbol{N}$ to $\boldsymbol{N ,}, \boldsymbol{\omega}$ to $\boldsymbol{\boldsymbol { \nu }}$, etc., suggest that it is unlikely to postdate the thirteenth century. The fragment may, however, be somewhat older.

The translation of Jannes and Jambres into Ge'ez took place at some point between the late fourth and sixth centuries, the time frame in which specialists agree that translational activity into Ethiopic directly from Greek transpired. Since the earlier part of this overlaps with the dates assigned to some of the papyri attesting the text, a date in the late fourth or early fifth century seems preferable insofar as the copying of the Apocryphon in Egypt implies its continued use among Christian groups there at that time. From its foundation the Ethiopian Orthodox Church was a daughter of the see of Alexandria and seems to have derived its literature from Egyptian Greek sources, and thus it is probable that Jannes and Jambres was translated while it was in at least fairly widespread circulation. ${ }^{6}$

The translator demonstrates a reasonably good knowledge of Greek and, in places that can be compared, his translation renders the Vorlage quite literally and faithfully. However, the process of transmission within the Ethiopian tradition over centuries has unfortunately resulted in the accrual of numerous corruptions (at least in this unique exemplar), rendering the text very difficult to read, and on occasion all but unintelligible.

before an existing one in regular ink, thus giving the superficial appearance of a major punctuation marker, and in f. $2 \mathrm{r}^{\mathrm{a}} 6$ a word divider is similarly inserted before the numerals after one in normal ink; neither of these should be considered punctuation, particularly as they would separate the numbers from the counted objects. After the numeral in f. $2 \mathrm{r}^{\mathrm{a}} 6$, a square of four dots in red ink appears with a single dot in regular ink in its centre. Since the sentence ends at this juncture, it is possible that this might represent a punctuation marker. However, the format of the spaces into which the rubrications are inserted changes at this point, with word dividers in normal ink no longer appearing at their ends, so this aberration may simply be a result of momentary confusion on the part of the rubricator regarding how best to execute his task.

${ }^{5}$ Cf. Maximous el-Antony, J. Bild, and A.M. Butts, An Early Ethiopic Manuscript Fragment (Twelfth-Thirteenth Century) from the Monastery of St Antony (Egypt), Aethiopica 19 (2016) 27-51.

${ }^{6}$ On the early Ge'ez translations from Greek, see now A. Bausi, Translations in Late Antique Ethiopia, in F. Crevatin (ed.), Egitto crocevia di traduzioni ( $\triangle \mathrm{IA} \Lambda$ ОГОI 1; 2018) 69-99. 
One particularly notable feature in relation to this is the frequent appearance of the first vowel order $(a)$ of certain letters in places where the sixth order $(e)$ is grammatically required, especially $\boldsymbol{\nabla}$ for $\boldsymbol{\boldsymbol { \lambda }}, \boldsymbol{h}$ for $\boldsymbol{h}$, and $\boldsymbol{\boldsymbol { n }}$ for $\boldsymbol{n}$. Most likely this resulted from a scribe, perhaps even the copyist of this fragment, copying from an ancient exemplar in which the vowels were not clearly distinguishable visually and thus defaulting to the form that he saw, i.e. the first order, except in instances such as common prepositions where he readily knew the correct form of the word. ${ }^{7}$ While these observations further underscore the antiquity of the translation, for semi-vocalized Ethiopic manuscripts of the type that may have led to such confusion between letterforms are both early and rare, ${ }^{8}$ if this situation is representative of the state of the text more broadly in medieval Ethiopia, it may have contributed significantly to its fall into disuse as it became too difficult to understand readily. ${ }^{9}$

\footnotetext{
${ }^{7}$ Palaeographical confusion of a similar sort is attested within the Aksumite Collection in another of the exceptionally rare pre-fourteenth-century non-biblical Ge'ez manuscripts, as well as in a few other cases; see A. Bausi, The >So-Called Traditio apostolica $<$ : Preliminary Observations on the New Ethiopic Evidence, in H. Grieser and A. Merkt (edd.), Volksglaube im antiken Christentum (2009) 291-321 at 299-300 n. 21, and idem, La nuova versione etiopica della Traditio apostolica: edizione e traduzione preliminare, in P. Buzi and A. Camplani (edd.), Christianity in Egypt: Literary Production and Intellectual Trends. Studies in Honor of Tito Orlandi (Studia Ephemeridis Augustinianum 125; 2011) 19-69 at 24-5 n. 20. However, erroneous vowel orders found frequently with both the abovementioned and other letters in Eth seem completely haphazard and exhibit no discernible pattern or logic. Therefore, it may also be that we are dealing with a careless scribe in this instance or somewhere in the recent transmission history of the text.

${ }^{8}$ The only more or less intact Ethiopic manuscripts known to exhibit a lack of clarity in their vowel markings in such a manner are Biblioteca Apostolica Vaticana, Vat. et. 263 and the second Abbā Garimā gospels codex.

${ }^{9}$ Letters in Eth are distinguishable from one another except for $\boldsymbol{\prime} \boldsymbol{i}$ and $\boldsymbol{\imath}$; these have therefore been transcribed according to the correct grammatical form in each instance.
} 
T.M. Erho \& W.B. Henry, The Ethiopic Jannes \& Jambres \& the Greek Original 181

f. $1 \mathrm{r}^{\mathrm{a}}$

[ : भind: : ehrhh :

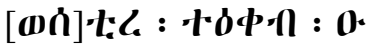

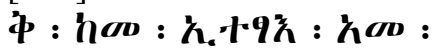

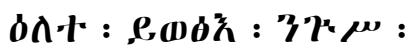

5

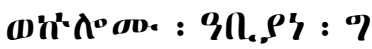

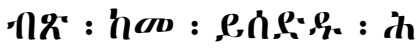

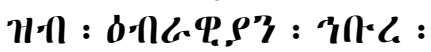

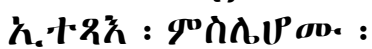

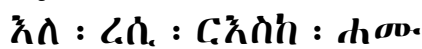

10

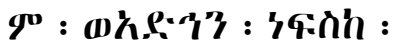

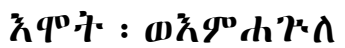

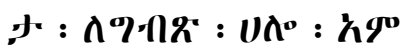

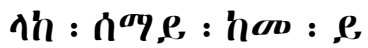

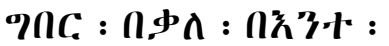

15

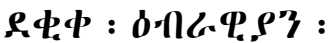

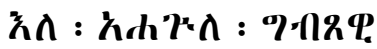

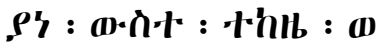

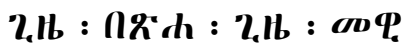

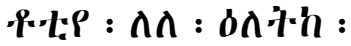

20 f. $1 r^{b}$

QP : $=000:+1.900$

"ลतกन: : 9,00,

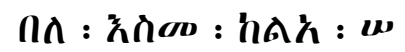

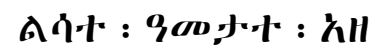

5

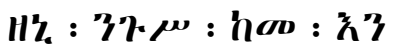

חC: $:$ hov : h.190\%: :

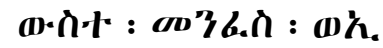

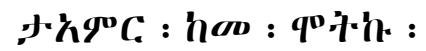

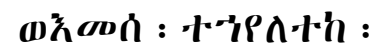

10

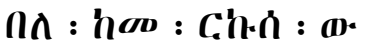

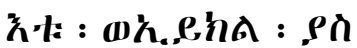

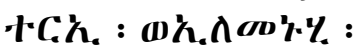

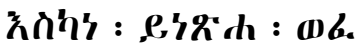

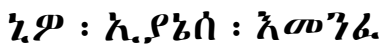

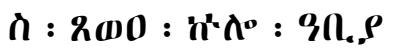

s : H\%नीR : oden. $\lambda^{\circ}$

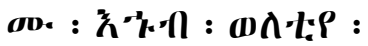

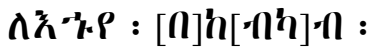

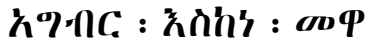

20

ठA : ती

$P: 0+1 \%$ : $1.1: 00 \%$

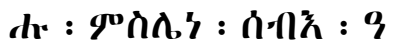

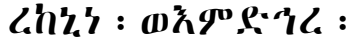

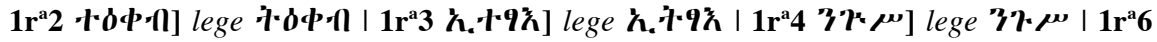

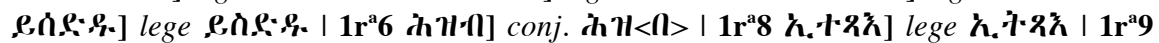

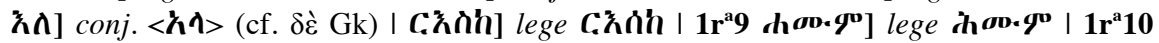

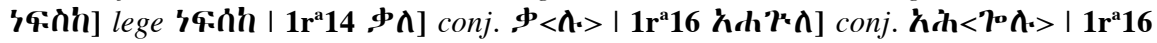

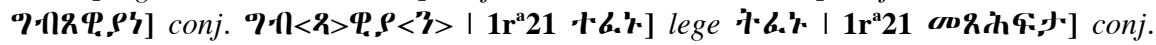

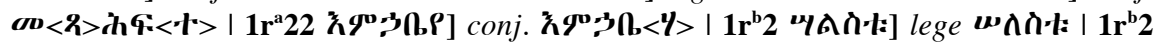

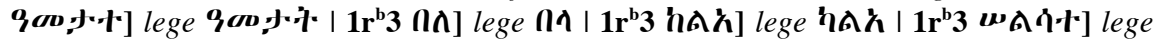

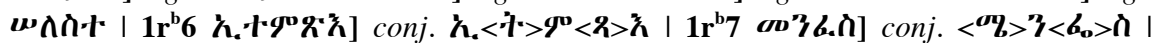

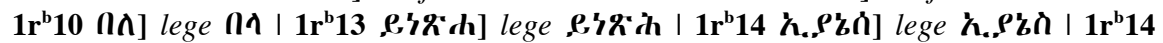

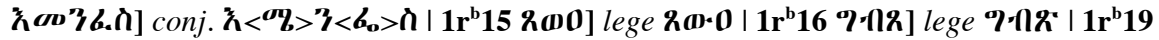

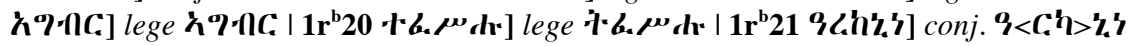


f. $1 v^{a}$

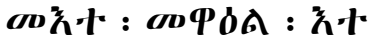

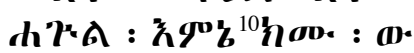

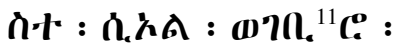

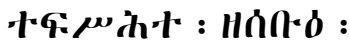
वั9dA : Hhनीhमी :

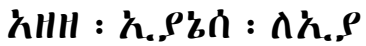

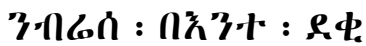
中: :

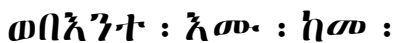

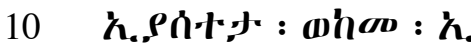
en o, : hov : h.thll

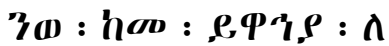
$\Lambda:$ onन : : $06.2 .9^{\circ}$ :

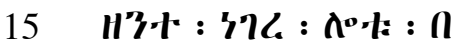

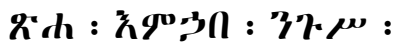

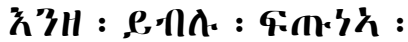
40\% : hook : +2.9 (19900. f. $1 v^{b}$

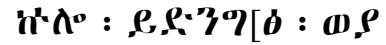

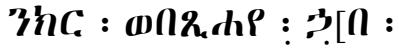

"7.

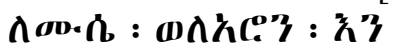

5

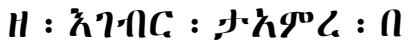

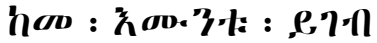

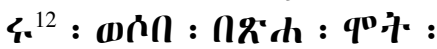

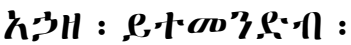

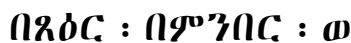

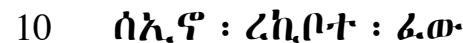
ก : 6.40 : 30 : 37.10 :

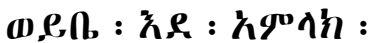

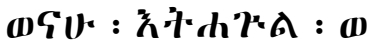

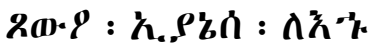

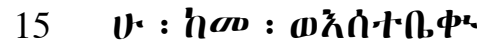

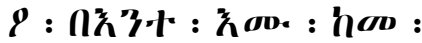

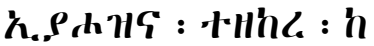

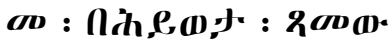

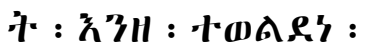

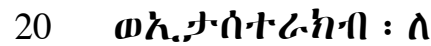

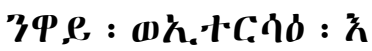

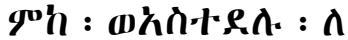

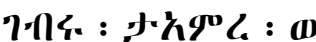
go'hlow : hoo :

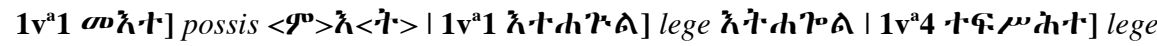

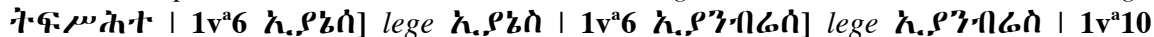

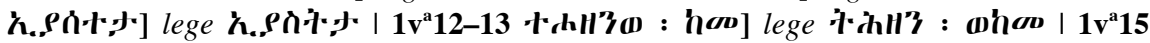

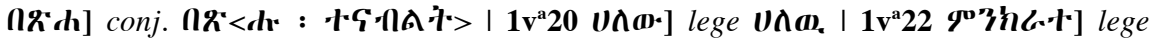

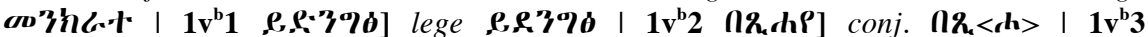

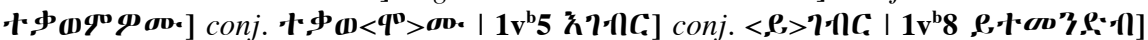

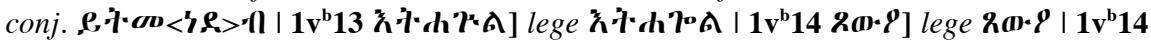

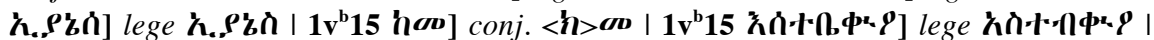

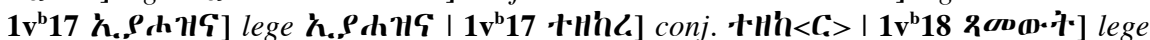

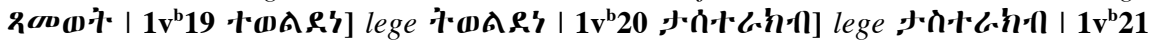

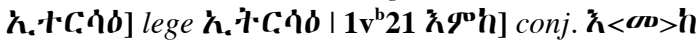

\footnotetext{
${ }^{10}$ Letter altered from $\mathbf{3}$.

${ }^{11}$ Letter altered from $\boldsymbol{n}$.

${ }^{12}$ Letter altered from $\boldsymbol{C}$.
} 
'(f. 1 $\mathrm{r}^{\mathrm{a}}$ ) “... [th]is is yours. [And a se]cret you should keep (it). Take care that you do not go out on the day the king and all the nobles of Egypt go out in order to pursue the people of the Hebrews! Do not go out together with them! $\langle\text { But }\rangle^{13}$ consider yourself sick and save your soul from death and from the destruction of Egypt. The God of Heaven will act according to $<$ his $>$ word on behalf of the children of the Hebrews, whom the Egyptians caused to perish in the river (cf. Exod 1:22). And when the time (for) me to die is nigh, daily go always to my mother. And you should send to me letters like this from (f. $\left.1 r^{b}\right)<$ her $>$. And when three years are completed, tell her that the king commanded me to remain (for) another three years, so that she shall not come to <Memphis> and not learn that I died. And if she (has) gained mastery (over) you, tell her ' $\mathrm{He}$ is unclean and he will not be able to show himself to anyone at all until he is cleansed"."

'And sending (out) from <Memphis>, Iyānnēs summoned all the nobles of Egypt, and he said to them, "I am giving my daughter to my brother [in] mar[ria]ge. I shall do (this) for seven days. And you will rejoice with us, men, our friends. And after (f. $1 v^{a}$ ) a hundred days ${ }^{14}$ I will be lost from you into Sheol." And making merry during the seven days of the wedding, Iyānnēs instructed Iyānbrēs about his children and about his wife and about his mother, that he should neither neglect nor abandon her even one hour lest she be grieved, and that he should visit her daily.

'And finishing this speech to him, <ambassadors> arrived from the king, saying, "Quickly come so that you might oppose the Hebrews, for they are doing signs and wonders so that (f. $\left.1 v^{b}\right)$ everyone is amazed and marvels." And reaching the king, $<$ he $>$ opposed Moses and Aaron (cf. 2 Tim 3:8), doing signs like they were doing. But then death arrived (and) took hold (of him). Tormented with a pain in the bottom and being unable to find a cure, he sent to the king and he said, "(It is) the hand of God (cf. Exod 7:5, 8:15)! And behold, I am perishing!"

"And Iyānnēs cried out to his brother <also>, and he pleaded to him about his mother, that he not sadden her: "Remember that in her life she endured giving birth to us! And let yourself neither accumulate wealth nor forget your mother. And prepare for ...",

\footnotetext{
${ }^{13}$ Here and elsewhere in the translation angle brackets mark emendations affecting the English rendering.

${ }^{14}$ Or, with emendation, 'those days.'
} 
$\left.1 \mathbf{r}^{\mathrm{a}} \mathbf{1} \boldsymbol{1 1}\right] \boldsymbol{\eta} \boldsymbol{1}$. Approximately three letters have been lost in the lacuna at the beginning of the first line. This probably includes the end of the verb governing the sentence opening the leaf, presumably corresponding to $\pi \alpha \rho \alpha \tau i \theta \varepsilon \mu \alpha \iota$ if that is correctly restored in B at $A b 1$ (cf. $\S$ II.i below).

$1 \mathbf{r}^{\mathrm{a}} 2[\boldsymbol{\omega n}] \cdot \boldsymbol{l}:$ l. Two letters have been lost in the lacuna at the beginning of the line with traces of ink from a leg of the second visible. The conjunction $\boldsymbol{\boldsymbol { D }}$ is possible as the first letter, as is the preposition $\mathbf{\Omega}$ reconstructed on the basis of the Greek $\dot{\varepsilon} v(A b 1)$. The relative pronoun $\boldsymbol{I}$ could be read also, with the entire fragmentary sentence then 'th]is is yours, [which] you should keep [hi]dden'.

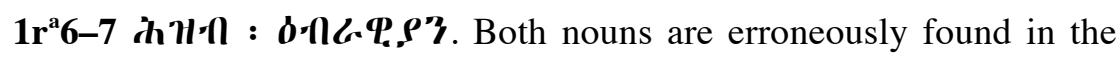
status absolutus rather than the genitival status constructus required linguistically and suggested by qùv $\lambda \alpha$ [ [ròv 'E $\beta \rho \alpha i ́ \omega v(A b 4)$, necessitating

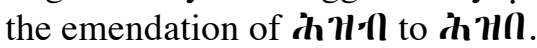

$1 r^{a} 9 \boldsymbol{\lambda}$. The common corruption of the conjunction $\boldsymbol{\lambda} \lambda$ into the relative pronoun $\lambda \lambda$ has occurred within the transmission of the Ethiopic text.

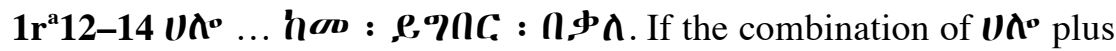
the subjunctive here is to indicate a prophetic voice (cf. S. Weninger, Das Verbalsystem des Altäthiopischen: Eine Untersuchung seiner Verwendung und Funktion unter Berücksichtigung des Interferenzproblems (2001) 271-2), then the intervening $\boldsymbol{h} \boldsymbol{\sigma o}$ is unusual and runs contrary to all of Weninger's examples. However, hov appears in front of the nearby subjunctives in Eth, and given its tendency to collocate with verbs of this type (cf. A. Dillmann, Lexicon linguae aethiopicae (1865) col. 5), it is uncertain whether its presence here necessarily violates the prophetic voice construction. Alternatively, $\boldsymbol{U} \boldsymbol{N}^{\mathbf{*}}$ might reflect a misreading of the relative pronoun $\dddot{\eta} v$ (supplied in Ab8) as the verb $\hat{\eta} v$ by the translator, in which case such a construction would not exist. As suggested by Getatchew Haile, the $3 \mathrm{~ms}$ pronominal suffix should be added to the noun $\mathbf{\Phi} \boldsymbol{\Lambda}$.

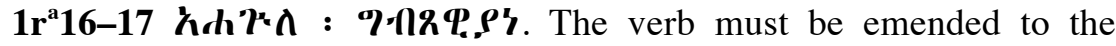
plural $\left(\boldsymbol{\lambda} \boldsymbol{h} \mathbf{7}^{\circ} \boldsymbol{\lambda} \cdot\right)$ from the singular and the following noun emended from

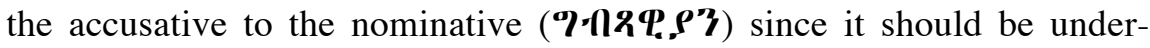
stood as the subject in view of the probable allusion to Exod 1:22.

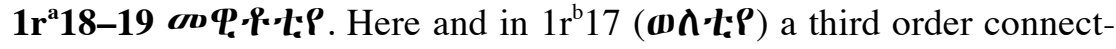
ing vowel appears in place of the standard sixth order. The alternation of the sixth $(e)$ and third $(i)$ orders before semivowel $y$ is however a common 
feature in early Ge'ez inscriptions and manuscripts; see further A. Bausi, Ancient Features of Ancient Ethiopic, Aethiopica 8 (2005) 149-69 (at 158).

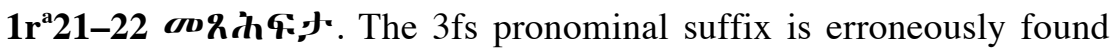
in the form taken by singular rather than plural nouns, and this solecism is

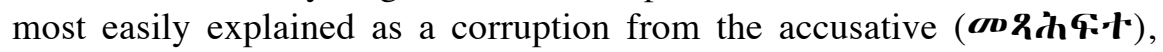
thus matching $\gamma] \rho \alpha ́ \alpha \mu \alpha \tau \alpha(A b 14)$.

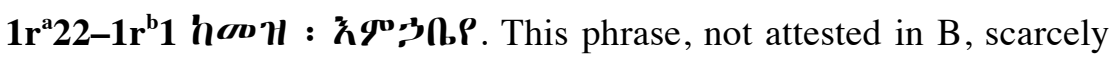
makes any sense as written. The most straightforward emendation is to read a $2 \mathrm{fs}$ pronominal suffix at the end rather than the $1 \mathrm{~s}$ form. While this gives a superficially understandable text, $\boldsymbol{h} \boldsymbol{\sigma o} \boldsymbol{t} \boldsymbol{t}$ implies an equivalency between the $\beta i \beta \lambda o \varsigma$ at the beginning of this scene $(\mathrm{V}$ fr. A.18 = B [4a $\rightarrow 20-21]$, p. 175 Pietersma) and these $\gamma \rho \alpha ́ \mu \mu \alpha \tau \alpha$ which seems a bit doubtful. The entire phrase serves, however, to make very clear that the dispatch of the letters is also part of the elaborate charade for the mother, not merely some unrelated task of Jambres. It is likely that a clarifying phrase such as $\dot{\alpha} \pi^{\prime} \alpha \hat{\imath} \tau \hat{\imath} \varsigma$ may have appeared in a form of the Greek text at some point to overcome the existing ambiguity, from whence it was translated into Ge'ez.

$1 \mathbf{r}^{\mathrm{b}} \mathbf{3} \mathbf{\Omega} \boldsymbol{\Lambda}$. A probable sight error has affected Eth both here and in $1 \mathbf{r}^{\mathrm{b}} 10$ below, where the imperative verb with the 3 fs pronominal suffix (ח介),

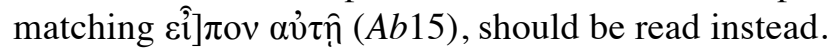

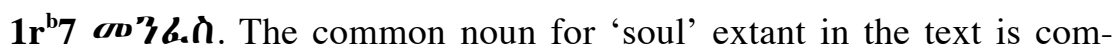
pletely nonsensical here and in $1 \mathrm{r}^{\mathrm{b}} 14-15$, and the wordform doubtless constitutes a corruption of some transliteration of 'Memphis'. Given the instability of certain transliterated names such as this in Ethiopic texts and the extant form of the word, it is probable that the text originally had a

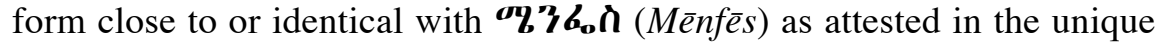
Ge'ez exemplar of the History of the Episcopate of Alexandria ( $\$ 21.13$ and §24.15). In fact, in a third instance that manuscript seems to reflect a

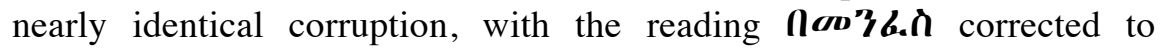

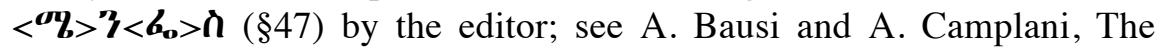
History of the Episcopate of Alexandria (HEpA): Editio minor of the Fragments Preserved in the Aksumite Collection and in the Codex Veronensis LX (58), Adamantius 22 (2016) 249-302 (esp. 290).

$\mathbf{1} \mathbf{r}^{\mathrm{b}} \mathbf{1 8}[\mathbf{0}]^{\mathbf{h}}[\boldsymbol{\bullet} \mathbf{n} \boldsymbol{h}] \cdot \mathbf{n}$. Neither the preposition nor the middle characters of the noun are legible due to contaminant on the parchment. 
$1 \mathbf{v}^{\mathrm{a}} \mathbf{1} \boldsymbol{\boldsymbol { \sigma o }} \boldsymbol{\lambda} \boldsymbol{\gamma}$. The simplest emendation for the nonsensical word form is to read $\boldsymbol{9 0} \boldsymbol{\mathbf { n }} \boldsymbol{\gamma}$ ('100'). This, however, seems rather specific, and nothing corresponding exists in B, though $\rho=100$ could be supplied at the end of

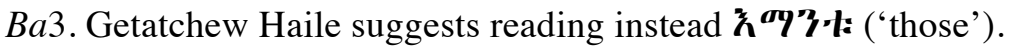

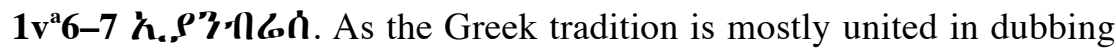
the brother 'I $\alpha \mu \beta \rho \eta \varsigma$, the Ethiopic tradition, if not corrupted internally, may reflect a manuscript in which a medial nu appeared in the name in place of the mu. Cf. Gignac, Grammar i 171. A very similar interchange

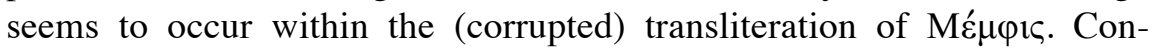
versely, the same transliteration for the brother's name appears in 2 Tim $3: 8$, and it may be that the Ethiopic textual tradition or translation was made to conform with this; cf. on $1 v^{\text {b } 2-5}$ below.

1va15-16 n\%: An emendation of the verb to a plural seems appropriate in view of $\pi \alpha \rho \eta \hat{\eta} \sigma \alpha$ in the Greek $(B a 13)$ and the following plural in Eth. The subject of this verb has been lost in Eth, but can be emended into

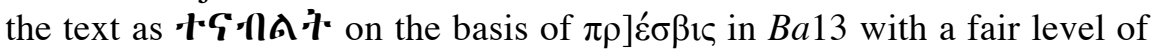
confidence since this translational equivalency is consistently attested throughout the Ge'ez Old Testament (e.g. Num 21:21, 22:5; Deut 2:26; Is 21:2, 39:1).

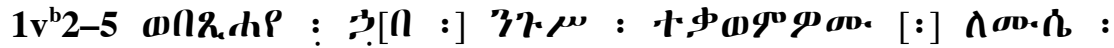

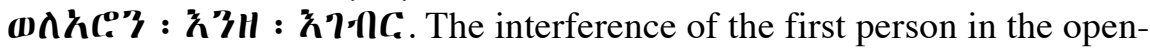
ing participle and final verb contrasts with the much more sensible Greek

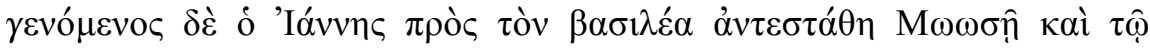

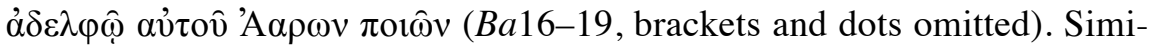
lar, albeit less obviously problematic, occurrences of the first person in

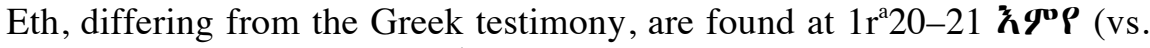

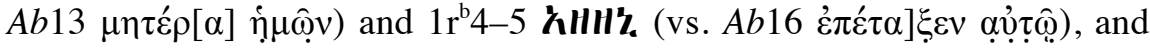
this pattern may be reflective of a clumsy attempt to make the narrativeor at least Jannes' part in it-come across more actively. The similarly awkward $3 \mathrm{mpl}$ form of the intervening verb probably represents an attempt to conform the text with the parallel passage in 2 Tim 3:8, where

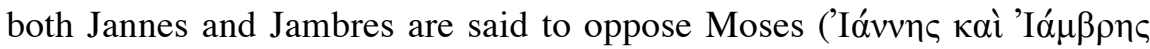

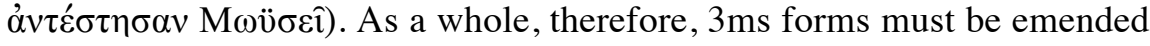
into this clause.

$1 \mathbf{v}^{\mathbf{b}} \mathbf{2} ?[\mathbf{n}$. Only the tip of the vowel marker of harm is extant.

$1 \mathbf{v}^{\mathrm{b}} 13 \boldsymbol{\hbar} \boldsymbol{\gamma} \boldsymbol{A}$. In this section, Eth obviously has a much shorter text than the Greek witnesses. This verb may, however, reflect a misreading by 


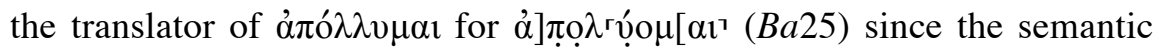
range of the former aligns very closely with the Ethiopic root found here (cf. W. Leslau, Comparative Dictionary of Ge' $e z$ (1987) 215).

$\mathbf{1} \mathbf{v}^{\mathbf{b}} \mathbf{1 5} \boldsymbol{h} \boldsymbol{\boldsymbol { \omega }}$. It is most likely that the particle hov has been corrupted to the much more common adverb/conjunction hov here, but alternatively possible that the Ge'ez text instead originally read hos'l ('like this'), with the zay having dropped out at some stage.

Due to the loss of the intervening leaves in Eth and the fact that the highly fragmentary concluding pages of B have yet to reveal any decisive textual overlap with its contents, it might be doubted whether the second Ethiopic leaf belongs to Jannes and Jambres. However, several factors, when considered in combination, create the overwhelming probability that it does.

The first pertains to the material evidence. Since Eth consists of an intact bifolium, the second leaf would have belonged no further than six leaves distant from the first in the original manuscript, assuming the usual quaternion structure.$^{15}$ Insofar as one side of the first Ethiopic leaf corresponds to approximately one page in $\mathrm{B}$ at that point in the manuscripts, and approximately 14 pages remain in B after the cessation of the overlap with Eth (cf. below, § II.iii), the maximum equivalent of 12 intervening pages keeps well within the boundaries of the Apocryphon. Moreover, the scribe of B squeezes more text onto each page from $5 a+\downarrow$ onwards and the second leaf of Eth contains 21 lines in contrast to the 22 of its predecessor: both of these elements reduce the 1:1 ratio and bring forward the approximate point within B at which the material from the latter half of the bifolium would in theory lie. Unless the bifolium has been refolded backwards (and no material evidence for this is evident), meaning that the second leaf actually represents part of the end of a preceding text, it is almost impossible to avoid the conclusion that it must physically constitute a fragment of Jannes and Jambres.

This claim is, however, buttressed by considerations of content. More

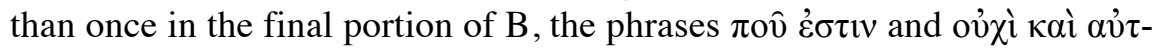
$\dot{\alpha} \pi \varepsilon \varepsilon_{\alpha} \alpha \nu$ - are encountered. ${ }^{16}$ These correspond perfectly with the repeated

\footnotetext{
${ }^{15}$ Old Ethiopic manuscripts do not contain page or leaf numbers and only occasionally possess quire numbers. It is not therefore surprising that there are no paratextual clues of this type to aid in the reconstruction of the manuscript.

${ }^{16}$ For the former, cf. $5 \mathrm{e}+\mathrm{g} \downarrow 7$ ( $\S$ II.ii(b) below) with note, and for the latter, $5 \mathrm{~h}+\mathrm{o} \rightarrow 3$ (§ II.ii(a) below) with note.
} 


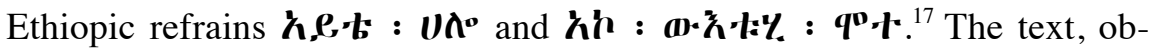
viously a translation from Greek, is significantly different from anything

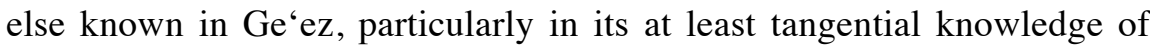
names found in Greek myths: cf. below on $2 \mathrm{r}^{\mathrm{b}} 7,2 \mathrm{v}^{\mathrm{a}} 10,2 \mathrm{v}^{\mathrm{b}} 17$. While the limited amount of text means that it cannot be entirely ruled out that it might be part of a work of an early Christian author, there are no clearly Christian references or allusions. Although the use of such material by a Christian author cannot be precluded, the allusion to 1 Enoch 7 suggests a Jewish milieu, and the Greek names a Hellenistic Jewish one, the same type of setting hypothesized for Jannes and Jambres. No other parabiblical Jewish apocrypha originating among the diaspora are known to have been translated into $\mathrm{Ge}$ ' $\mathrm{ez}$, so either we would hypothetically have a bifolium representing two otherwise unknown translations, or one; Occam's razor implies the latter position to be preferable. ${ }^{18}$ Given the lack of any confirmed overlaps between it and $\mathrm{B}$, it does, however, remain

\footnotetext{
${ }^{17}$ Series of rhetorical questions beginning with $\pi$ ôิ $\dot{\sigma} \sigma \tau \imath v$ are found elsewhere, such as 4

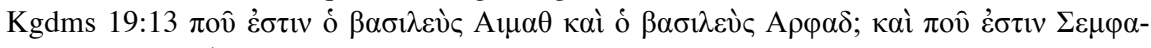
povaıv, Ava кai Ava; M.L. West, The East Face of Helicon: West Asiatic Elements in Greek Poetry and Myth (1997) 552-3, gives some further passages of this type. In all of these cases, those named are deceased elites or mythological characters, but normally their absence from the land of the living is mentioned collectively or simply implied through the question(s) and related context. Only in Jannes and Jambres does repeated and specific reference to each figure's mortal state seem to occur.

${ }^{18}$ An additional possible consideration involves the image connected to the Latin excerpt or paraphrase of a passage of Jannes and Jambres in the eleventh-century manuscript London, BL, Cotton Tiberius B V Part I (cf. P. McGurk et al. (edd.), An Eleventh-Century Anglo-Saxon Illustrated Miscellany (1983)). In the illustration on f. 87v (facsimile 28 in McGurk et al.; pl. 19 Pietersma; <http://www.bl.uk/manuscripts/Viewer.aspx ?ref=cotton_ ms_tiberius_b_v!1_f087v>), a gigantic wild figure reaches out of the underworld. Pietersma (279) speculates that this might be Satan, but fallen angels or evil spirits play a much greater role in contemporary Jewish writings, and the devil seldom materializes. If Satan appeared in the Apocryphon, one would expect such an antagonist to serve an at least somewhat significant function, but no evidence whatsoever exists for any demonic figures in the narrative: Jannes and his brother, and to a lesser extent their family and Pharaoh, play the role of the wicked. Might it therefore be that this is instead pictorial evidence for the presence of giants in Hades within the text? Henry however prefers to think that the figure grasping souls on the left is simply a monster like the others shown tormenting souls, and that its large size, balancing that of the rock on the right, is due to considerations of artistic composition, noting that there is no evidence of knowledge of any part of the book besides the fragment contained in the manuscript itself in Anglo-Saxon England: see F.M. Biggs and T.M. Hall, Traditions Concerning Jamnes and Mambres in Anglo-Saxon England, Anglo-Saxon England 25 (1996) 69-89 at 89.
} 
possible that multiple recensions of Jannes' paenitentia circulated in Greek, and that these two witnesses reflect different forms of the end of the text. ${ }^{19}$ Perhaps giants became included due to the references to $\tau \grave{\alpha}$

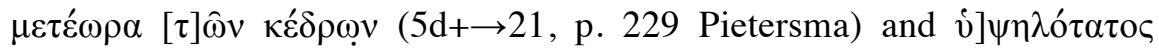
$\dot{\alpha} v \theta(\rho \omega ́) \pi \omega[v(5 \mathrm{~d}+\mathrm{k} \rightarrow 3, \S$ II.ii(a) below) .

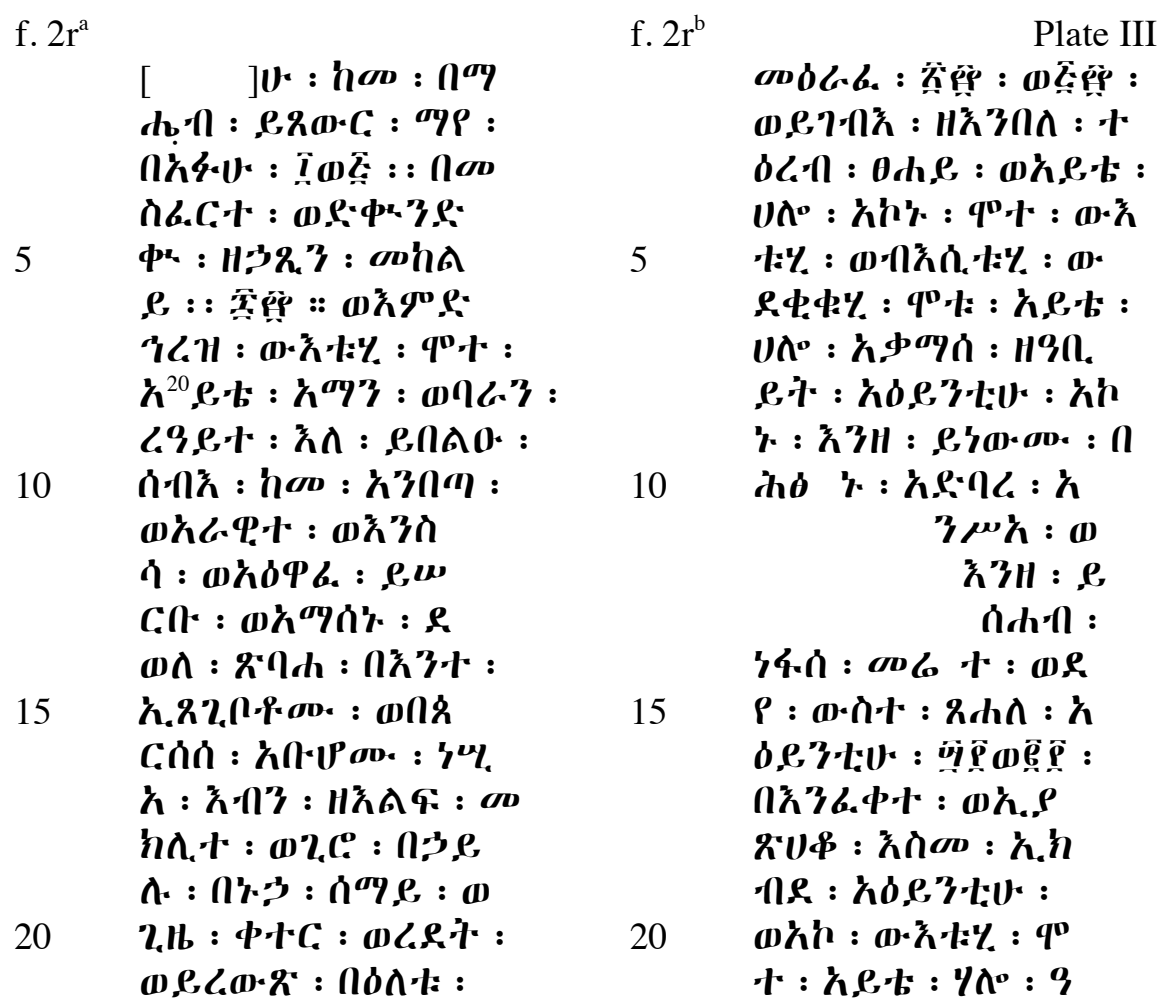

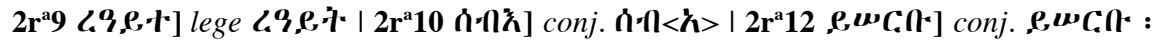

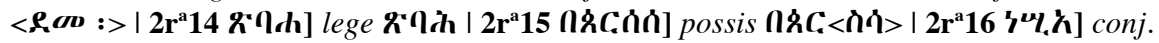
',

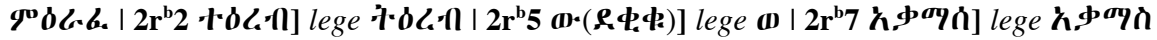

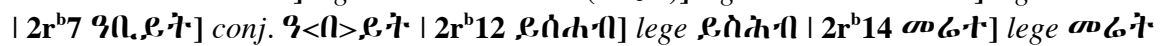

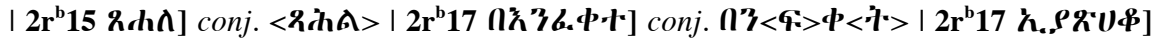

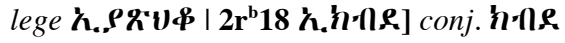

\footnotetext{
${ }^{19}$ This possibility was suggested by A. Pietersma in personal correspondence.

${ }^{20}$ Letter altered from $\boldsymbol{\hbar}$.
} 


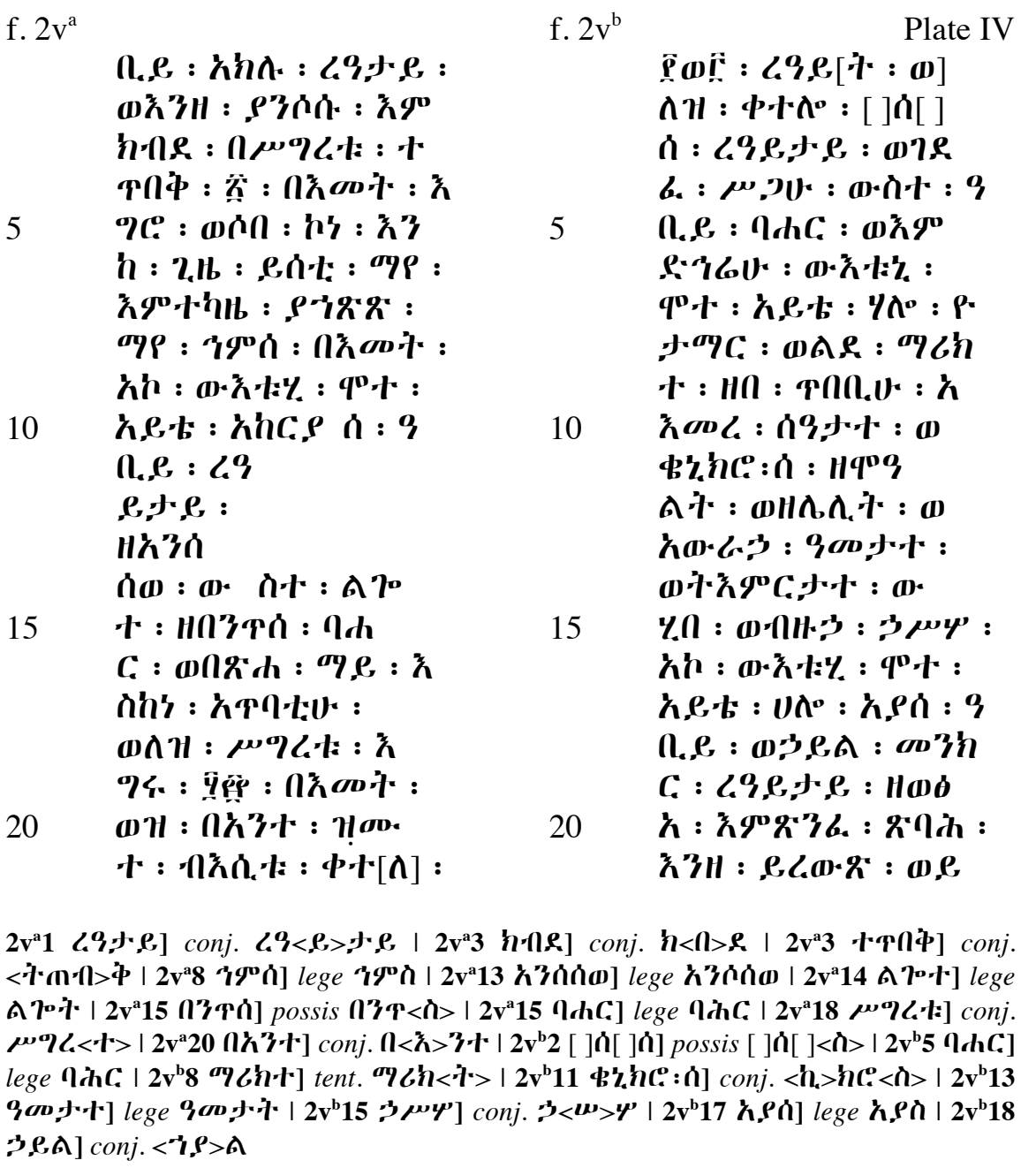

'(f. $\left.2 \mathrm{r}^{\mathrm{a}}\right)$... that he (could) carry water in a bucket (which fit) in its mouth 15 (units) in measure, and an axe of iron (weighing) 600,000 talents. But later even he died!

'Where are Amān and Bārān, the giants who devoured men like locusts and wild animals and cattle and birds? They drank <blood> (cf. 1 En. 7:45 ) and despoiled the Orient ${ }^{21}$ because they (could) not be satisfied. How-

\footnotetext{
${ }^{21}$ Lit. 'region of the East'. This translation adheres to the most common semantic ranges for the words. However, öpoৎ and öpoৎ were not infrequently confused by Ethiopian translators; cf. Jub. 16:10, and more significantly for the present text, since the same
} 
ever, Bapares, their father, lifting a stone of a thousand talents, threw it by his own strength into the height(s) of heaven. And noontime descended, and he ran that same day (f. $2 \mathrm{r}^{\mathrm{b}}$ ) 250,000 stadia and returned before the sun set. And where is he? Did he not die? Even he and his wife and his children died!

'Where is Aqāmās, whose eyes were huge? Did he not, while they were sleeping, with his belly raise up mountains? And since the dust storm was drawn out, he placed in a $<$ bowl $>$ his eyes in 4,200 pieces, but it did not concern him, for heavy <were $>$ his eyes. And did not even he die?

'Where is the gr(f. $\left.2 v^{a}\right)$ eat Aklu, the gigantic? When walking, from the weight of his steps, 20 cubits (of earth) adhered to his feet. And when therefore it happened one time (that) he drank water from the river, it decreased the water (by) five cubits. Did not even he die?

'Where is the great Akaryās, the gigantic, who walked in the depths of the Bantes(a) Sea and the water reached (only) up to his breasts? To this one (belonged) footsteps of 500,000 cubits, and, because of his wife's adultery, he killed (f. $2 \mathrm{v}^{\mathrm{b}}$ ) 103 gian[ts. And] this one killed [ ]sa[ ]s the gigantic and cast his body into the Great Sea. But afterwards even he died!

'Where is Yotāmār, son of Māriket, who in his intelligence understood the hours and minutes of the day and of the night, and the months of the years, and the signs given? And much (else) he investigated. Did not even he die?

'Where is Ayās, the great and mighty, the marvellous, the gigantic, who left the eastern frontier running and ...?'

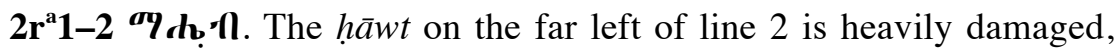
with its top missing, but the identity of the basic character is discernable. It is more difficult to determine its associated vowel, but there appear to be traces of the loop of the fifth order. Though a substantive form of the root is not listed by Leslau, Comparative Dictionary 337, this is taken to be derived from "9h9 ("draw water with a large container, dip, plunge'), with yaman assimilating into the vowel order of the preceding character.

collocation appears in the Ge'ez translation, Num 23:7, where it seems to correlate to

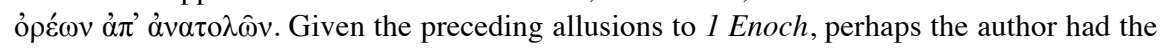
description of the East in chs. 29-32 in mind here. 
$2 \mathbf{r}^{\mathrm{a}} \mathbf{1 0} \boldsymbol{n} \boldsymbol{n} \boldsymbol{n}$. Given the probable allusion to $1 \mathrm{En}$. 7:4, this noun should be considered the object, not subject, of the preceding verb, and hence emended to the accusative.

2ra12-13 ewC:1- The allusion to or paraphrase of the end of 1 En. 7:5 suggests that 'blood' ( $\boldsymbol{\rho} \boldsymbol{\sigma o})$ has dropped out of the text from after this verb.

2rat5-16 M\&Cin. It is uncertain how best to vocalize the end of this name given the confusion between the vowel orders of $s \bar{a} t$ elsewhere in Eth: nkCan (Baparsas) is the most conservative emendation. However, given the contrast between this figure and his sons, it may be that the second $s \bar{a} t$ represents the particle $\boldsymbol{\mathbf { h }}$, used here to draw emphasis to the difference between the generations. The latter interpretation has been adopted.

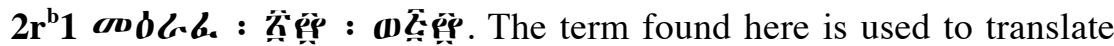
$\sigma \tau \alpha ́ \delta 10 v$ in Lk 24:13, John 6:19 and 11:18, and Rev 14:20; cf. Jub. 10:21. Given the text's origin, it seems virtually certain that the unit of measurement in question was the ubiquitous stadion. It is tempting to speculate that Eratosthenes' equivalent measurement for the circumference of the earth is in view (cf. Cleomedes, Caelestia 1.7.109-10), with the idea being that Bapares was able to run around the world in less than half a day. For further references to 250,000 stadia and related figures in antiquity, see A.C. Bowen and R.B. Todd, Cleomedes' Lectures on Astronomy (2004) 84 n. 22. The Ethiopic numerals follow the object being counted rather than precede it in the more customary fashion, with their terminal positioning quite likely occasioned by the Greek word order.

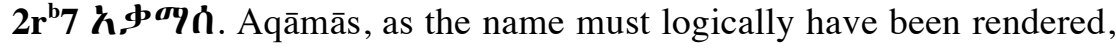
appears to be a transliteration of 'Aка́ $\mu \alpha \varsigma$.

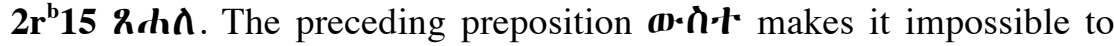
read a verb here, necessitating its emendation to the closest noun, RAA.

2r ${ }^{b} 18-19$ h.h.hl. The prefixed negative particle makes little sense, and thus probably should be considered an error, one perhaps mistakenly inserted as a result of the negative preceding verb.

$2 v^{\mathrm{a}} 10$ hhC:Pn. Akaryās is possibly a somewhat corrupted transliteration of "Iкароц. 
$2 v^{a} 15$ M"zan. Since Greek names commonly end with sigma, most likely this transliteration should be understood as Banțes. It is not impossible in this case, however, that the final first order should be read exactly as written, i.e. Bantesa. Alternatively, if the preceding noun is found in the accusative case, the prefixed zay might not be a genitive marker, but part of the name, with Zabanțes and Zabanțesa then also possible renderings.

2va 20-21 1000-r. Only the legs of zay can be discerned beneath the contaminant on the parchment.

$\left.2 \mathbf{v}^{\mathrm{a}} 21 \boldsymbol{\phi} \cdot \boldsymbol{r} \cdot \mathbf{\Lambda}\right]$. The writing surface is completely obscured beneath an overlying contaminant at the end of this line: it is not clear whether lāwi stood there or was mistakenly omitted by the scribe.

$\mathbf{2} \mathbf{v}^{\mathbf{b}} \mathbf{2}-\mathbf{3}[$ [ ] $[$ [ ] $\mathbf{n}$. The parchment is too damaged to determine the first and third character of the name of this giant, though some form of $m \bar{a} y$ seems most probable in the former case given the width of the letter and the few discernable ink traces. As elsewhere, the final character likely represents a sigma and should be read as a sixth order.

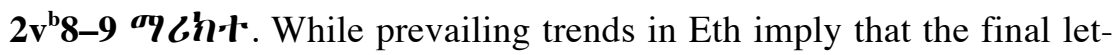
ter in this name should be read as a sixth order, thus giving the name of the father as Māriket, it cannot be precluded in view of the Semitic nameform that it might be read Māriketa as written.

$\mathbf{2 v} \mathbf{v} \mathbf{1 1} \mathbf{d} \mathbf{z}_{\mathbf{h}} \mathbf{h} \mathbf{c}: \mathbf{\mathbf { n }}$. This term, which neither matches any known Ge'ez word nor any Greek one in transliterated form, must in this context denote a unit of time. Getatchew Haile suggests emending to $\boldsymbol{h}_{\mathbf{q}} \boldsymbol{h} \mathbf{e} \boldsymbol{n}$.

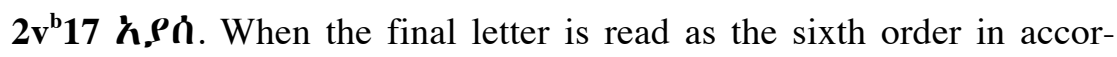
dance with the final sigma found in most Greek names, the transliteration Ayās appears to correspond to Aỉac. 


\section{The Greek original}

II.i. I present below a fresh edition of the three pages of B that include the part of the Greek text translated on the first leaf of Eth. The more ambitious supplements are meant exempli gratia, but it has seemed worthwhile even when the papyrus is at its most fragmentary to determine as far as possible whether or not B has room for a Greek text corresponding to Eth; and even a speculative reconstruction may facilitate the identification of further fragments.

The pages in question, whose original sequence is established for the first time by Eth, are those published by Pietersma as frame 4abdefi $\downarrow$ (p. 185) and frame $3 a b \rightarrow$ and $\downarrow$ (pp. 151 and 167). For the sake of clarity and simplicity, I refer to them as $A b$ (frame 4abdefi $\downarrow$ ) and $B a$ and $B b$ $(3 \mathrm{ab} \rightarrow$ and $\downarrow$ ); the previous page, Pietersma's frame 4abdefi $\rightarrow$ (p. 175), will be cited as $A a$. I suggest below ( $\S$ II.iii) that leaves $A$ and $B$ are the second and third of the codex.

Half-brackets in the text $(A a 24-A b 8, B a 14-B b 8)$ mark the contribution of $\mathrm{V}$ frr. A (18-25) and B, which are now seen to have come in that order; the text lost between them will have filled a column. ${ }^{22}$ Uncredited supplements are taken over from Pietersma's edition; my own are indicated with an asterisk. The apparatus does not record readings or supplements that are now excluded for whatever reason, or places where $\mathrm{V}$ has a different spelling. The readings of $\mathrm{V}$ are given in articulated form, and supplements taken from earlier publications are given in the apparatus in the form in which they appear in the present text.

I have inserted additional fragments as follows:

1. $4 \mathrm{~g} \downarrow$ (p. 184 Pietersma) at $A b 20-21$. On the other side of the leaf,

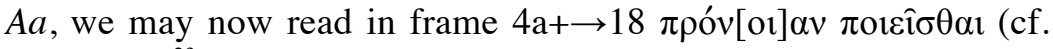
Henry 66$)^{23}$ and in the next line $\pi \alpha \rho \alpha \kappa[\alpha] \lambda \hat{\omega} y$ where Pietersma gives $\pi \alpha \rho \alpha \lambda[\alpha \beta \omega ́ v] .^{24}$

\footnotetext{
${ }^{22}$ The text overlapping the last line (25) of $\mathrm{V}$ fr. A comes at B Ab8 and that overlapping the first line of $\mathrm{V}$ fr. B (a column of 23 lines) at B Ba14. The missing column of $\mathrm{V}$ will thus have held a passage corresponding to 30 lines of $\mathrm{B}$. The lines of $\mathrm{V}$ hold slightly more text than those of $\mathrm{B}$, and there is no reason to suppose that a missing column of about 25 lines would have been too short to accommodate in full the text as given by B.

${ }^{23}$ The pi of $\pi$ orєî $\sigma \theta \alpha$ is divided between $4 \mathrm{~g} \rightarrow 1$ and $4 \mathrm{~b} \rightarrow 3$. In the former, Pietersma (174) reads $\alpha v \tau$, but the last letter is broken on the right, and pi is equally acceptable.

${ }^{24} \mathrm{~V}$ fr. A.16 has $\pi \alpha \rho \alpha \lambda[$, and Maraval supplies $\pi \alpha \rho \alpha \lambda[\alpha \beta \omega ́ v$, adopted by Pietersma, but in $\mathrm{B} 4 \mathrm{a}+\rightarrow 19$, the trace following $\pi \alpha \rho \alpha$ is the top of an upright: kappa can be read, but
} 
2. $3 \mathrm{c}$ and e at the top of leaf $B$. See Henry $61-3$.

3. $8 \mathrm{~d} \downarrow$ (p. 259 Pietersma) at the top of $B b(1-4)$. This fragment is blank on the other side where the top sheet has come away at a sheet join.

4. 1ef (pp. 125 and 129 Pietersma) at the foot of leaf $B$ (Ba18-27, $B b 19-27)$. With these fragments in place, it is clear that only two lines come below Pietersma's frame $3 a b \rightarrow 18(B a 25)$ at the foot of the page; the gap between his lines 18 and 20 is eliminated, as is that between his lines 17 and $20(B b 24-5)$ on the $\downarrow$ side. This join produces virtually continuous text, of considerable interest, in the lower part of $B b$, for which Eth is unavailable.

The original height of each of these leaves is now seen to be about 27 $\mathrm{cm}$.

Plates V-VII

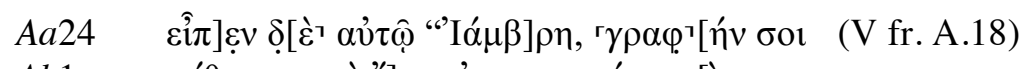

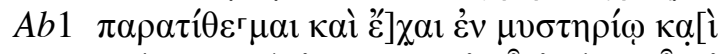

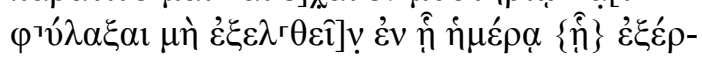

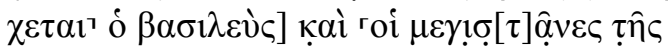

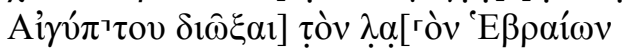

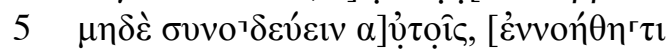

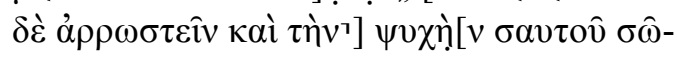

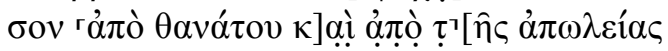

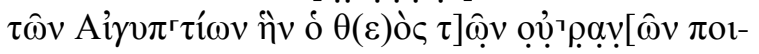

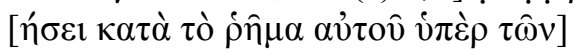

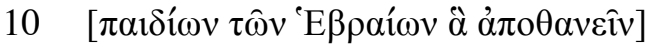

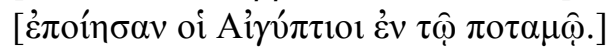

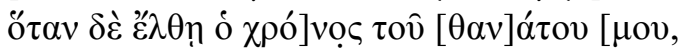

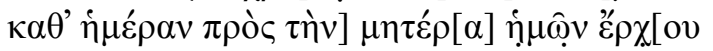

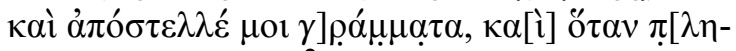

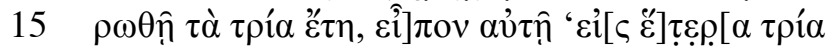

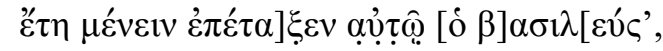

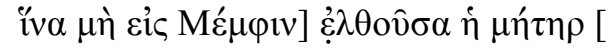

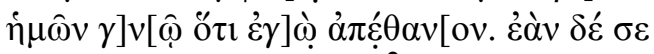

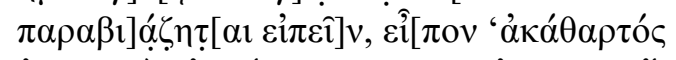

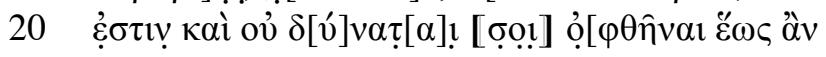

hardly lambda. Then in $\mathrm{B} 4 \mathrm{~g} \rightarrow 2$, Pietersma prints $\lambda \omega \sigma$, but virtually none of the final letter is preserved following the link stroke. $\pi \alpha \rho \alpha \kappa \alpha \lambda \hat{\omega} v$ may have taken the place of $\pi \alpha \rho \alpha \lambda \alpha \beta \omega \omega^{\prime}$ through the influence of $\pi \alpha \rho \alpha \kappa \alpha \lambda \varepsilon \dot{\varepsilon} \sigma \varsigma$ just before (V fr. A.15 = [B 4a+ $\rightarrow 18])$. 


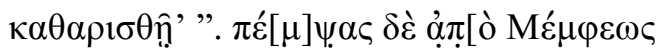

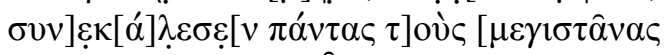

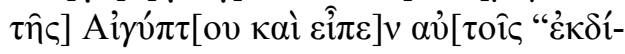

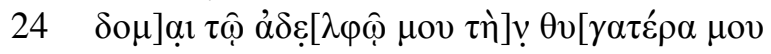

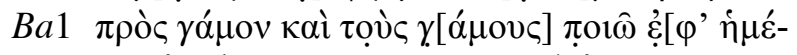

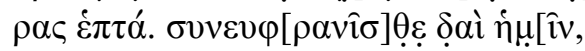

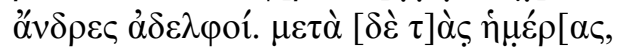

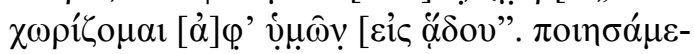

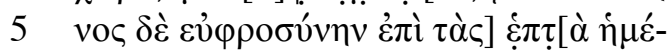

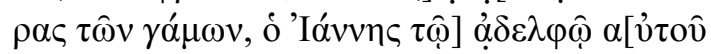

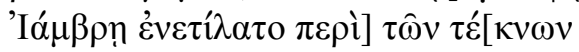

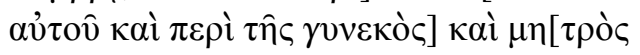

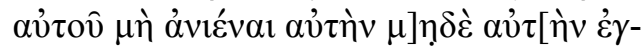

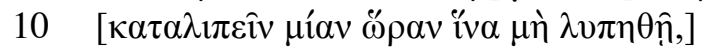

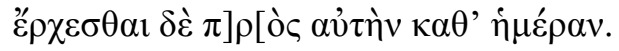

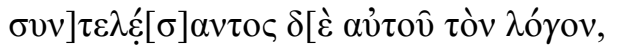

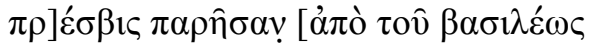
$\lambda \varepsilon ́$ ].

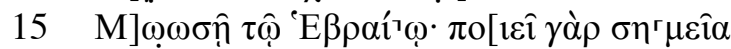

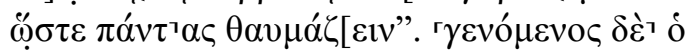

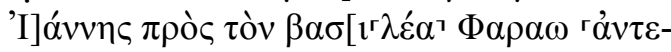

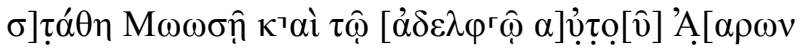

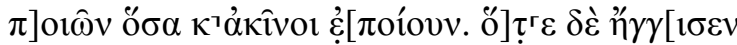

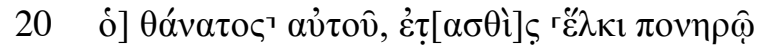

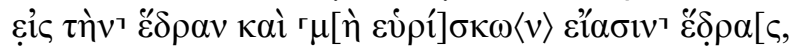

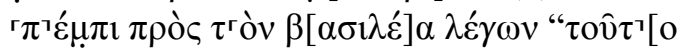

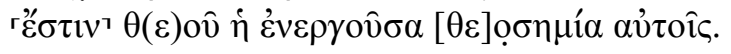

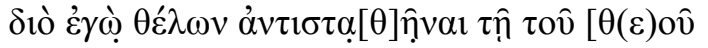

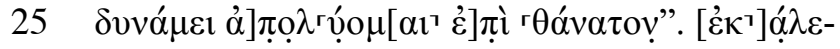

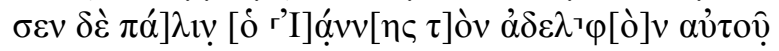

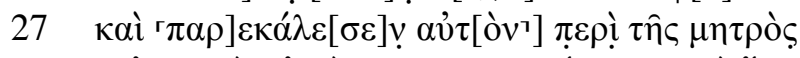

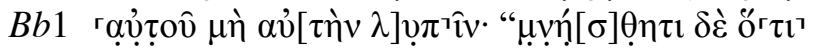

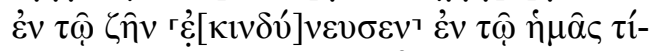

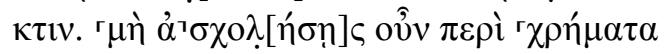

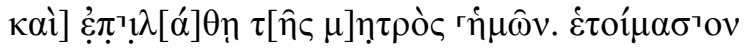

]. $\alpha 1 \kappa .[$

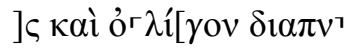

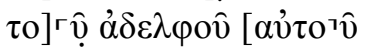


T.M. Erho \& W.B. Henry, The Ethiopic Jannes \& Jambres \& the Greek Original 197

10

15

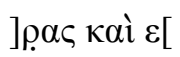
]. ọ 'Í́vỵ[n

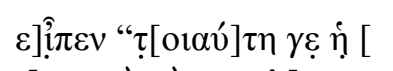

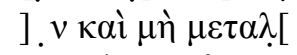

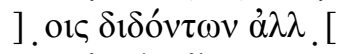

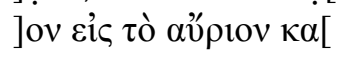
]v $\tau \grave{\alpha} \delta \grave{\varepsilon} \tau \eta \rho o u ́ \mu \varepsilon v \alpha \varepsilon$. [

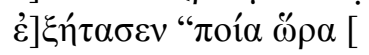

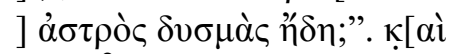

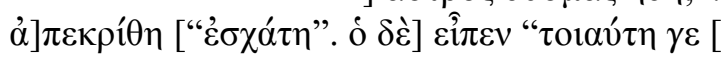

$20 \dot{\eta} \dddot{\omega} \rho \alpha \tau \hat{\omega} v \dot{\alpha} \mu \alpha \rho[\tau \omega] \lambda \hat{\omega} v \kappa \alpha \grave{\delta} \delta$ o $\lambda \dot{\omega} \omega v \kappa \alpha \rho[\delta 1 \hat{\omega} v$,

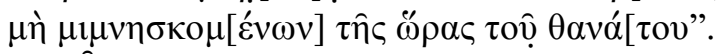

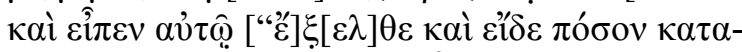

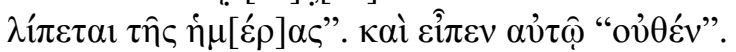

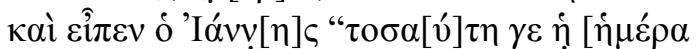

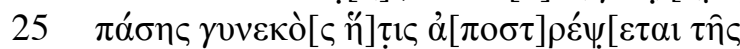

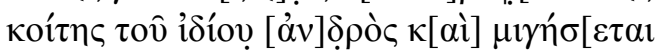

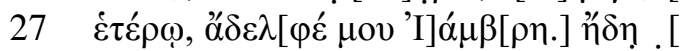

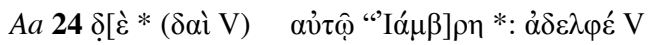

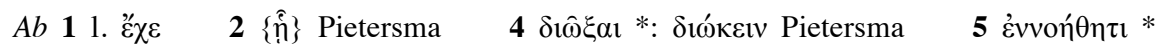

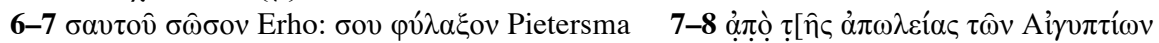

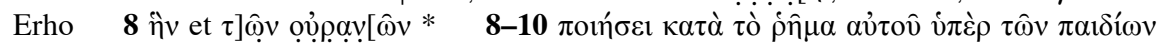

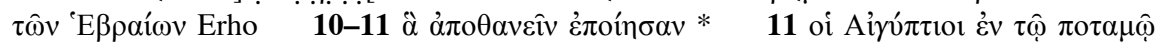

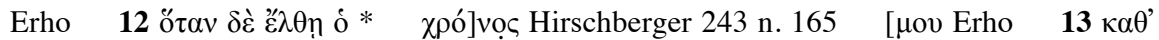

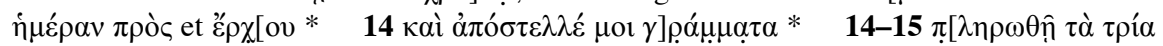

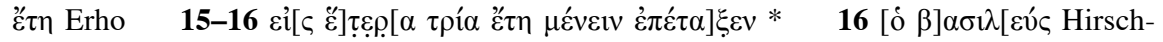

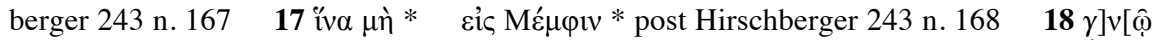

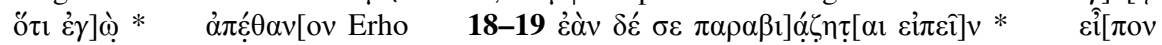

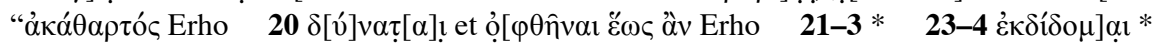

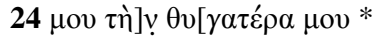

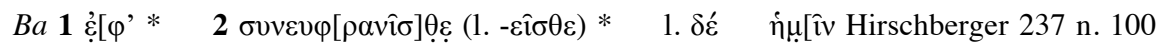

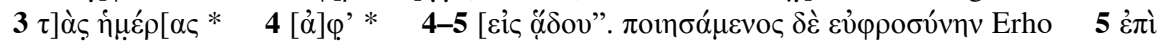

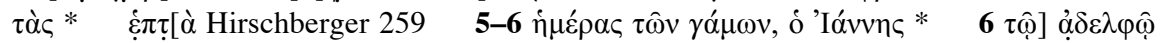

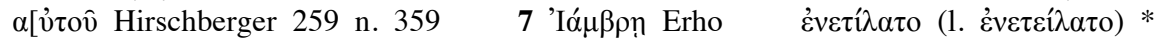

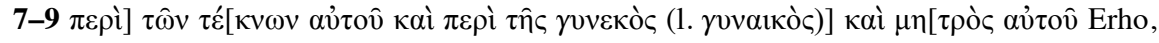

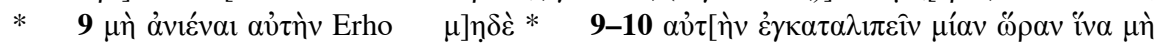

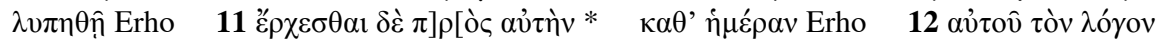

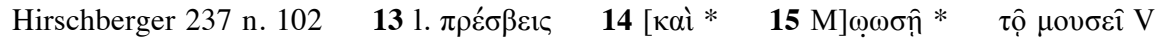

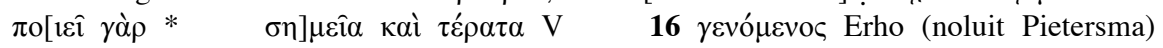




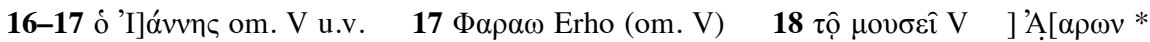

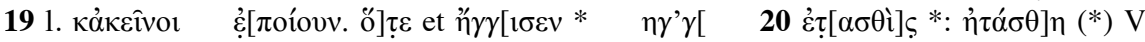

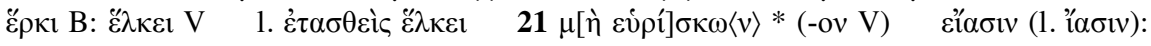

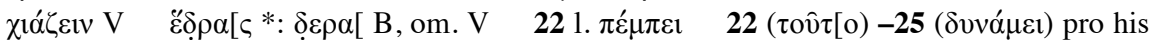

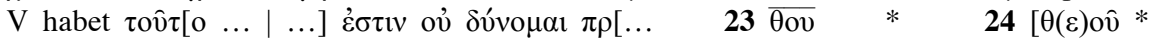

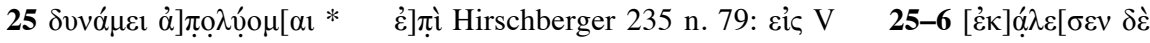

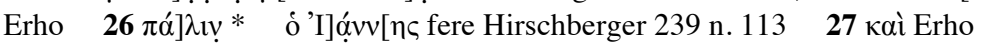

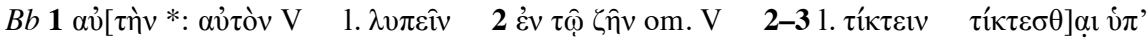

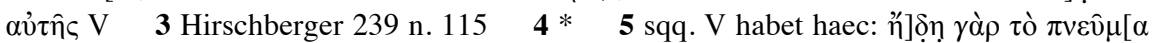

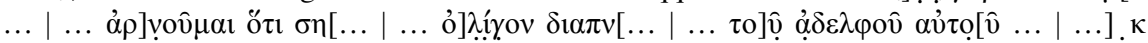

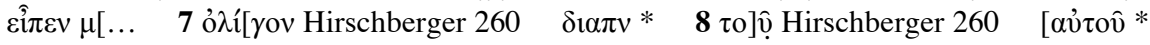

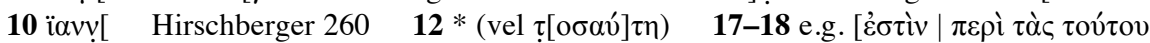

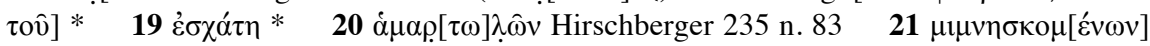

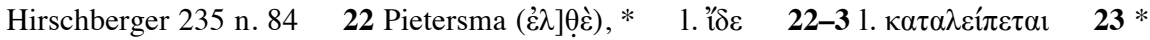

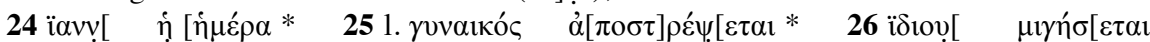
Hirschberger 239 n. 130

'And he (Jannes) said [to him,] "Jambres, [I hand over to you] a document $[A b]$ [and] keep it in secret and [take care not to come out] on the day on which [the king] and the chiefs of [Egypt] come out [to pursue] the people [of the Hebrews nor to go along] with them, [but plan to be unwell and save your own] soul [from death] and from [the destruction of the Egyptians which the god] of the heavens [will carry out according to his word on behalf of the children of the Hebrews whom the Egyptians caused to die in the river. And when the] time of [my] death [comes], go [every day to] our mother [and send me] letters, and when [the three years are completed,] tell her, 'The king [commanded] him [to remain] for another [three years', so that our] mother [will not] go [to Memphis and find out that I have] died. [But if she compels you to say,] say, 'He is [impure] and cannot [be seen until] he is purified" ". And sending word [from Memphis,] he convened [all] the [chiefs of] Egypt [and said to] them, ["I am giving away my] daughter to [my] brother $[B a]$ in marriage and I am celebrating the [wedding for] seven days. And you will rejoice together with us, dear brothers. [And] after the days, I depart from you [to Hades". And after making merry for the] seven [days of the wedding, Jannes instructed his] brother [Jambres concerning his] children [and concerning his wife] and mother [not to neglect her] nor [to abandon] her [for one hour lest she be pained, but to go to her every day. And when he had] completed [his speech], ambassadors were present [from the king,] saying, "Come quickly [and oppose] Moses the Hebrew: [for he is] making [signs] so that everyone is amazed". [And] Jannes, [having come] to the 
king [Pharaoh,] opposed Moses and his [brother] Aaron, doing as many things as they [were doing.] But [when] his death neared, tormented by a bad sore in his bottom and not finding a bottom remedy, he sent word to the king, saying, "This is God's miracle that is operating for them. Therefore I, wishing to oppose the [power of God,] depart to death". [And] Jannes called his brother again [and] entreated him concerning his mother $[B b]$ not to pain her: "But remember that she took a risk in life in giving birth to us. Do not then be occupied about money [and] forget our mother. Get ready ..." (...) and [after getting] a little [breath ... his] brother ... and ... Jannes ... said, "Such indeed (is) the ... and not ... giving to ... for the morrow ..., and the ... being observed ... (Jannes) questioned (Jambres): "Of what kind [is] the hour now [around the] setting of [this] star?" And he (Jambres) replied, ["The last." And he (Jannes)] said, "Such indeed (is) the hour of sinful and deceitful hearts, which do not remember the hour of death". And he (Jannes) said to him (Jambres), "Come out and see how great (a part) is left of the day". And he (Jambres) said to him (Jannes), "None". And Jannes said, "So great indeed (is) the [day] of every woman who will turn away from [the] bed of her own husband and have intercourse with another, Jambres [my] brother. Now ...",

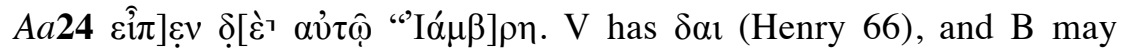
have had the same spelling: cf. $B a 2$. Then Pietersma's supplement $\tau \hat{\widehat{\varphi}}$ 'Ió $\mu \beta] \rho \eta ̣$ seems too short for the gap, whose length is given by the supplements on the other side of the leaf. Jambres was referred to in the previous sentence, and the pronoun seems possible here.

$A b 4 \delta 1 \hat{\omega} \xi \alpha \mathrm{l}]$. The aorist is supported by $2 \mathrm{~h} 3 \mathrm{~g} \rightarrow 9$ (p. 191 Pietersma) $+\mathrm{H}$

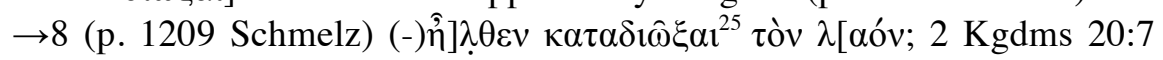

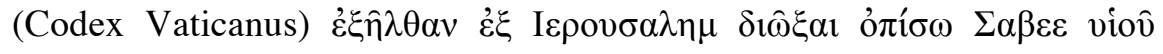

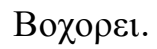

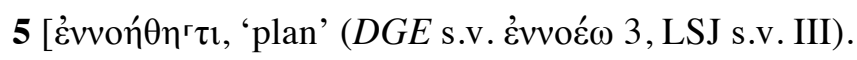

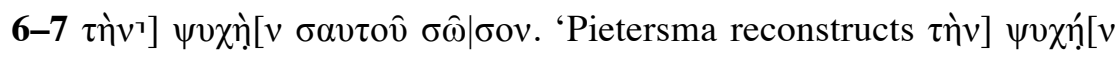

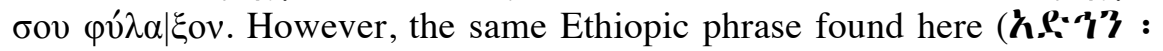

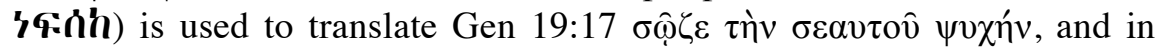
similar phrases elsewhere, e.g. $1 \mathrm{Kgdms} \mathrm{19:11,} \mathrm{Jas} \mathrm{5:20,} \mathrm{the} \mathrm{same} \mathrm{verb}$ always renders $\sigma \omega_{\zeta}^{\zeta} \omega^{\prime}$ (TME).

$\left.{ }^{25}\right] \ldots \delta 1 \omega \xi \varepsilon$ B. Pietersma read $\varepsilon \pi ! \delta 1 \omega \xi \varepsilon$ there, but the traces at the start are exiguous, and there is no need to suppose that the two copies diverged from each other. 


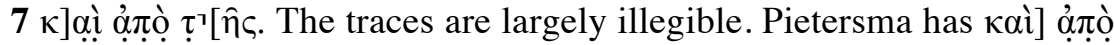

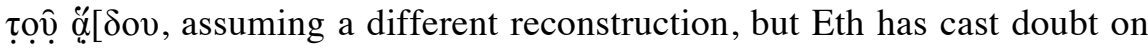
this.

$8 \tau 10 v^{26}$ (for - $\tau \iota \omega v$ ) stands at the start of the final line of $\mathrm{V}$ fr. A (25), and we must assume that the scribe of that papyrus divided Airv $\pi] \mid \tau$ íov incorrectly. Such an error is not excluded in a production of this quality: the orthography of $\mathrm{V}$ is poor and the hand inexpert. For false syllabification, cf. e.g. the medical questionnaire P.Oxy. LXXX 5238, assigned to the second/third century, and the documentary examples in Gignac, Grammar i 327-9.

ท̆ $v$ seems to be the only suitable interpretation of V's $\eta v$ (fr. A.25). 'While this appears to disagree with Eth, it is not impossible that the translator mistook the relative pronoun $\dddot{\eta} v$ for the verb $\hat{\eta} v$, which he rendered $\boldsymbol{U} \boldsymbol{\lambda}^{\circ}$ in the usual manner' (TME; cf. further $\S \mathrm{I}, 1 \mathrm{r}^{\mathrm{a}} 12-14 \mathrm{n}$.).

Oellacher supplies $\tau$ òv oủ[ $\rho \alpha v o ́ v$ in V fr. A.25, but the accusative singular is hard to accommodate in this sentence. Omicron was no doubt written for omega in both terminations, as in Ai $y v \pi] \mid \tau$ íov at the beginning of the line and elsewhere in $\mathrm{V}$ (fr. A.8 $\dot{\alpha} \pi \circ \sigma \tau \varepsilon \lambda \hat{o}, 11 \pi[1] \sigma \tau \hat{\jmath} \varsigma$, etc.). 'Eth seems to represent instead the genitive singular as part of the Ge'ez equiv-

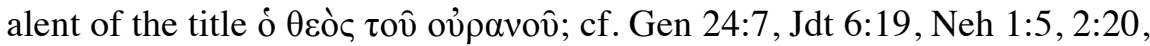
Ezra 1:2, 2 Chr 36:23, Dan 2:44' (TME).

9-11 The gap in B had been assumed to be two lines long on the basis of an apparent correspondence between the text on the other side $(4 \mathrm{a}+\rightarrow 8)$ and that of V fr. A.3 (Henry 63-4), but three lines are required to accommodate the Greek implied by Eth. With a gap of three lines here, the height of the leaf matches that of the next (approximately $27 \mathrm{~cm}$ ). B may then have had a longer text than $\mathrm{V}$ in the passage on the other side: there is some slight reason to suppose that the correspondence in the preceding lines was also not particularly close (Henry 64).

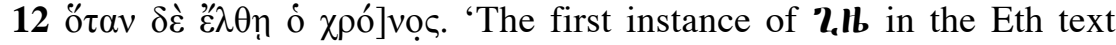
should not be understood substantively, but taken together with the verb as a temporal marker (cf. Leslau, Comparative Dictionary 210; T.O. Lambdin, Introduction to Classical Ethiopic (Ge'ez) (1978) 403), here

\footnotetext{
${ }^{26}$ So rightly Oellacher and Maraval. The omicron is damaged at the top left-hand corner but otherwise clear; neither omega ( $\omega$ Pietersma) nor alpha (Pietersma, Fragments) seems to suit the traces.
} 
equivalent to ö $\tau \alpha v$. The second instance of the term is a normal substantive usage ( $\chi \rho o ́ v o \varsigma)$ ' (TME).

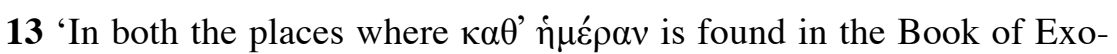
dus $(5: 13,16: 5)$, the Ethiopic translation renders it $\boldsymbol{\Lambda} \boldsymbol{\Lambda}: \boldsymbol{\delta} \boldsymbol{\lambda} \boldsymbol{\gamma}$, the same formulation attested here. In other texts, $\kappa \alpha \theta^{\prime} \dot{\eta} \mu \varepsilon \dot{\varepsilon} \rho \alpha v$ is more commonly

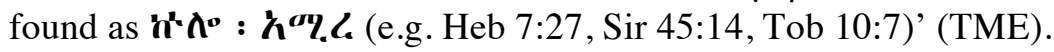

$14 \gamma] \rho \alpha ́ \mu \mu \alpha \tau \alpha$. Pietersma read and supplied $\kappa \alpha] \tau \alpha \rho \alpha ́ \mu \alpha \tau \alpha$, but the first trace appears to be the right-hand side of the loop of rho; then the traces before the second mu suit another mu, damaged to the right of the upright. Eth $1 \mathrm{r}^{\mathrm{a}} 22-1 \mathrm{r}^{\mathrm{b}} 1$ presents a longer, somewhat corrupted text: see $\S \mathrm{I}$.

ö $\tau \alpha v$ is correctly read by Erho: the loop of omicron is complete, and Pietersma's sigma seems excluded.

At the end, $\pi$ [ seems slightly preferable to $\tau$ [ (Pietersma): the preserved part of the crossbar, to the left of the upright on the edge, is quite narrow.

15 हi] $] \pi$ ov. For the accent of the imperative, restored again at 19, cf. J. Wackernagel, Philologus 95 (1943) 179-81 = Kleine Schriften ii 87880; P. Walters (formerly Katz), The Text of the Septuagint: Its Corruptions and Their Emendation, ed. D.W. Gooding (1973) 99-100.

$\varepsilon] \tau \varepsilon \rho[\alpha$. Of $\rho[$, the D-shaped loop is preserved, joined on the left by the upper curve of $\varepsilon$, abraded at the lower left-hand corner. Low traces to the left will represent ] .

$16 \dot{\varepsilon} \pi \varepsilon ́ \tau \alpha] \xi \varepsilon v$. A very low v-shaped trace near the edge suits the tail of xi, turning up at its tip.

$18 \dot{\varepsilon} \gamma] \omega \grave{\alpha} \alpha \dot{\varepsilon} \theta \alpha v[o v$. There is a short link-stroke joining alpha on the left at the start, compatible with omega, as in $24 \tau \hat{\varphi} \hat{\alpha} \delta \varepsilon[\lambda \varphi \hat{\varphi}$. Then the papyrus is damaged to the left of the theta, and there is no reason to prefer omicron (Pietersma) to epsilon.

$19 \pi \alpha \rho \alpha \beta 1] \alpha \hat{\alpha} \zeta \eta \tau[\alpha 1$. Before eta and extending under its left-hand side, the end of an oblique descending from left to right below the line and curling up at the tip: zeta seems possible. Before it, a trace on the line in place for alpha.

$\varepsilon i \pi \varepsilon \hat{]}] v, \varepsilon \hat{i}[\pi \mathrm{ov}$. The infinitive is not represented in Eth: perhaps it had dropped out through parablepsy. 


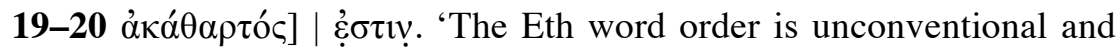
reflective of the underlying Greek; identical translational equivalencies are found in Lev 13:11, 13:36, Num 19:13' (TME).

$20 \delta[v] v \alpha \tau[\alpha]$. Of $\tau[$, the upright with the crossbar broken on the right.

[бọl]. A double ascending oblique extending across the full width of the word apparently serves to cancel it.

$21 \kappa \alpha \theta \alpha \rho \iota \sigma \theta \hat{n}$. Of the eta, the top of the first upright touching the lefthand end of the crossbar.

$\dot{\alpha} \pi\left[{ }_{0}\right.$ Mé $\mu \varphi \varepsilon \omega \varsigma$. The second trace is the foot of an upright, the first perhaps the lower edge of an arc.

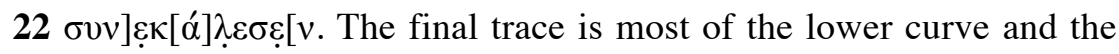
lower edge of the upper curve of $\varepsilon$ : not $\delta$ (Pietersma), which would be expected to project to the left at the top.

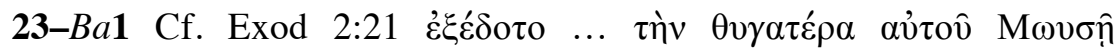

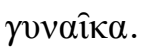

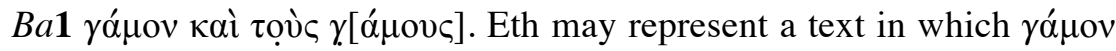

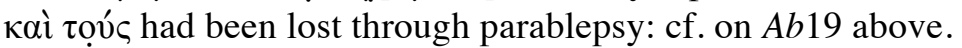

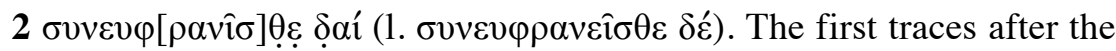
break are ambiguous ( $\eta \tau \alpha$ l Pietersma): perhaps the oval of $\theta$ with the crossbar projecting to the right and touching the left-hand side of $\varepsilon$. Then an upright trace in the lower half of the line and a crossbar at letter-top level to its right may belong to a delta of the kind used in $\alpha^{\prime \prime} v \delta \rho \varepsilon \varsigma$ in the next line. Erho notes that the future tense of the verb is compatible with the corresponding Eth imperfect.

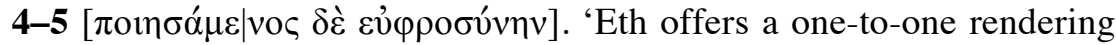
of the components of this phrase, making for unusual Ge'ez but offering some certainty as to the underlying Greek reconstructed here. For the use

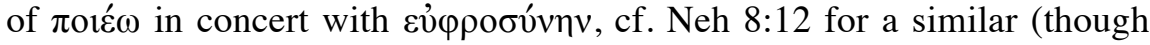
non-participial) case in both Greek and Ethiopic' (TME).

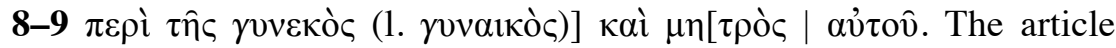
may be carried over from the first to the second of a pair of substantives joined with кaí: cf. Blass-Debrunner-Rehkopf, Grammatik des neutestamentlichen Griechisch § 276.1. 
$9 \mu] \eta \underline{\delta \varepsilon}$. The first trace is the top of an upright: eta is no less suitable than nu ( $(\underline{\text { Pietersma) }}$.

$11 \pi] \rho[$ óc. The rho is 'a trace of an upright hooked to the right and descending below the line' formerly taken as part of $3 \mathrm{ab} \rightarrow 4$ due to a false join (corrected at Henry 63).

$14 \dot{\varepsilon} \lambda \theta \dot{\varepsilon}$ [. There appears to be a low trace following the theta. I have tentatively adopted the imperative, suggested by Erho on the basis of Eth,

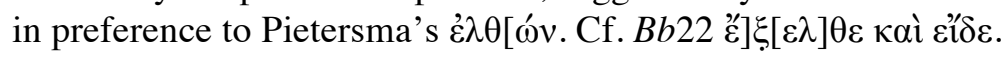

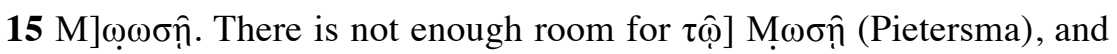
we expect the same spelling as in line $18 \mathrm{~V}$ has the article in both places (fr. B.1, 4), but B appears not to have had it in either.

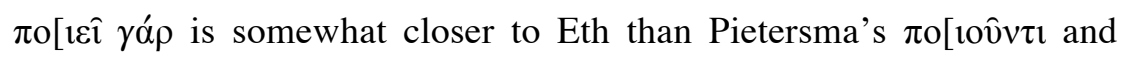
gives a simpler construction.

16 ' $\gamma \varepsilon v$ ó $\mu \varepsilon v o \varsigma \delta \delta \grave{r}$ ó. Eth seems to support the participle, for which $V$ fr. B.3 has the spelling $\gamma \varepsilon v \alpha ́ \mu \varepsilon v o c$. I have moved Pietersma's o here from the beginning of the next line, where there is not sufficient room for it.

17 Ф $\alpha \alpha \omega$. Erho suggests that this was added here as a gloss; it is not present in V fr. B.4. With it, the line will be of an acceptable length.

19 ö $] \tau\ulcorner\varepsilon \delta \varepsilon$. V fr. B.6 has $] \delta \varepsilon \delta \varepsilon$ (cf. Oellacher: ' $]\{\delta \varepsilon ?\} \delta \varepsilon$ '), with a high crossbar on the edge above $] \delta$, perhaps correcting o] $\delta \varepsilon$ to o] $\tau \varepsilon$. The first trace there is a cross-stroke on the line meeting a descending oblique to give a sharp point on the right: only delta seems suitable. The next letter closely resembles the $\varepsilon$ before $\eta \kappa \imath \sigma \varepsilon v$ (on which cf. the next note): most of the back is lost to abrasion, but we have the base, a much-extended upward-sloping crossbar, and a speck in place for the end of the cap. Maraval read ] $\pi \varepsilon$ in a photograph, but pi is excluded: it does not account for the flat stroke on the line at the start. Pietersma's ] $\varsigma_{\varsigma}$ does not seem to suit the traces.

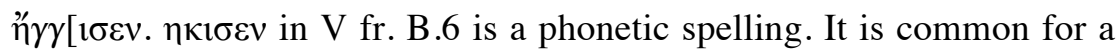
medial nasal to be omitted before a velar stop, and kappa frequently takes the place of gamma (Gignac, Grammar i 116, 76-80). Editors have under-

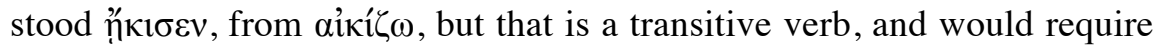
an expressed direct object (in this sentence av่óv).

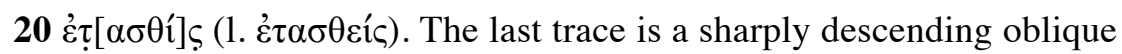
high in the line, suiting the cap of sigma. The first trace in $\mathrm{V}$ fr. B.7 
appears to represent the right-hand side of eta (so Oellacher and Maraval):

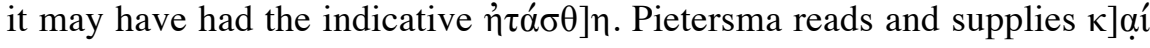
in $\mathrm{V}$, but the upright seems too short to be a ligatured iota: contrast e.g. \&l in the next word.

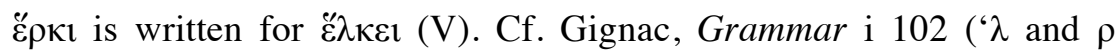
interchange frequently'), and e.g. J. Ziegler (ed.), Ieremias, Baruch, Threni, Epistula Ieremiae (Septuaginta 15; 1957) 116.

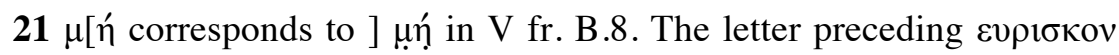
in that copy has hitherto been read as $v$, but the traces are two uprights, and $\eta$ is no less likely. The preceding $\mu$ is represented only by the final stroke joining the first upright of $\eta$ on the line.

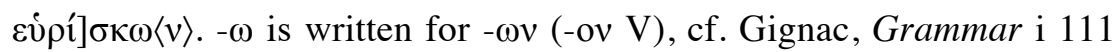
('final $-v$ is very frequently omitted'); Ziegler (as above, $20 \mathrm{n}$.) 119, who notes that the supralinear bar often substituted for $v$ at the end of a line could easily be missed by copyists.

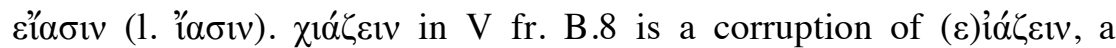
phonetic spelling of " $\alpha \sigma \sigma v$ with $\varepsilon 1$ for $\iota$ and $\zeta$ for $\sigma$ (for the latter interchange, cf. Gignac, Grammar i 120-24). The origin of the chi is obscure.

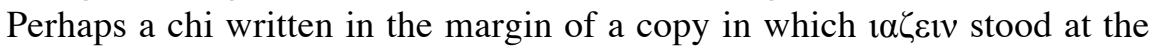
beginning of the line was wrongly taken as part of the text. For marginal chi indicating a passage of interest, cf. the examples opposite lines 48-9 of the fourth-century Deuteronomy codex P.Ryl. I 1 (Rahlfs 920; image: $<$ https://luna.manchester.ac.uk/luna/servlet/s/777x18>); K. McNamee, Sigla and Select Marginalia in Greek Literary Papyri (Pap. Brux. 26; 1992) 19-21. It is also conceivable that $1 \alpha \zeta \varepsilon v v$, taken at face value as the infinitive of iá $\zeta \omega$, which has no suitable sense, was conjecturally emended

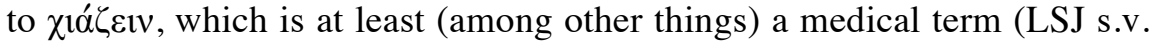
II.3: 'make a cruciform incision'), though hardly suited to this passage.

$\varepsilon \check{\delta} \rho \alpha[\varsigma . V$ fr. B. 8 does not include this superfluous word. B appears to have $\delta \varepsilon \rho \alpha$ [, an example of 'scribal inversion of letters' (Gignac, Grammar i 315). $\delta$ is damaged at the upper left-hand corner, and Pietersma's $\sigma$ may not be excluded, but we do not expect a reference to Sarapis, and there is in any case no room at the end of the line for $\Sigma \varepsilon \rho \alpha{ }^{2}[\pi \mathrm{i} \delta$ o or the like.

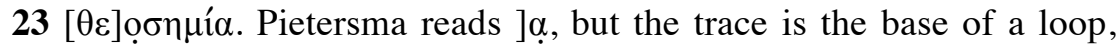
and omicron, if written like the last of the next line, seems a good fit. 
$24 \dot{\alpha} v \tau \imath \sigma \tau \alpha[\theta] \underline{y} v \alpha \imath$. The final iota is joined to the tail of the preceding alpha and has on its right the upward-sloping left-hand side of the crossbar of tau: for the combinations, cf. $\mu \mathrm{t}$ in the previous line and $\eta \tau$ immediately after. $v$ (Pietersma) is not a possible reading.

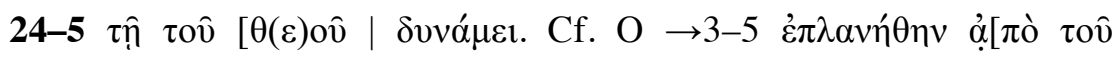

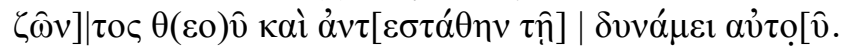

$25 \dot{\alpha}] \pi \underline{0} \lambda$ r tight loop of alpha is clear. Oellacher prints ] $\mu \alpha ! !$, but Maraval gives ] $\varepsilon \hat{\imath}$ $\mu \eta$, and Pietersma ]. $\mu$ ń.

26-7 Vertical fibre continuities indicate that the innermost fragment, $3 \mathrm{~b}$, belongs slightly nearer the outer edge than Pietersma's text implies. The supplement lengths have been adjusted accordingly at the start.

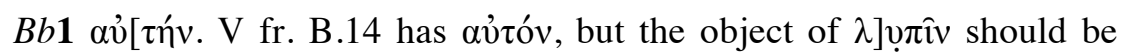
expressed. The corruption may be due to the influence of av่ óv in the previous line. It is also conceivable that $\mathrm{V}$ had a different text in what precedes; but Eth agrees with B.

12-27 The new join sheds some light on the situation here. Jannes appears to be illustrating for Jambres the idea that sinners are punished with death. He may have continued, e.g., 'So too all those such as myself who oppose the power of God are punished with death; and now I shall die'.

22 ' $] \xi[\varepsilon \lambda] \theta \varepsilon$. $\xi$ is represented by a tail that crosses the alpha of $\alpha \varsigma$ in the line below just below its apex. So in line 18 the scribe writes over the extended tail of the xi of $\dot{\varepsilon}] \xi \dot{n} \tau \alpha \sigma \varepsilon v$ in the line above.

$\varepsilon \nmid \delta \varepsilon$ (1. ' $\delta \varepsilon$ ). For the accent, cf. Walters (as above, $A b 15$ n.) 100; P. Probert, Ancient Greek Accentuation: Synchronic Patterns, Frequency

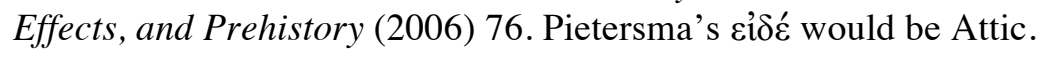

$23 \dot{\eta} \mu[\varepsilon \dot{\varepsilon} \rho] \alpha \varsigma$. For the reading $\eta \mu[$ in 1 ef $\downarrow 5$, see Henry 60 . Pietersma has $\lambda$ before $\alpha \varsigma$, but the additional trace belongs to the preceding line: see above on 22 है] $] \xi \varepsilon \lambda] \theta \varepsilon$.

$24 \grave{i}$ [. The trace is the top of an upright hanging from the crossbar of $\varepsilon$ : $\eta$ is no less likely than Pietersma's $v$.

$25 \dot{\alpha}[\pi \circ \sigma \tau] \rho \varepsilon \dot{\varepsilon} \psi[\varepsilon \tau \alpha$. Of $\psi[$, only the lower part of the upright and the turn-up survive: Pietersma's $\rho$ is the most obvious reading, as the traces correspond to those of the previous rho, but psi appears no less acceptable. 
$27 \eta n \delta \eta$. Pietersma reads $\eta \delta ! ̣$, , but there is a clear crossbar joining the two uprights after $\eta \delta$. It is true that there is a little surplus ink at the lefthand end of the crossbar touching the first upright, corresponding to Pietersma's o, but eta still seems probable, and it produces a suitable word.

II.ii. None of the text translated on the second leaf of Eth has been found among the Greek remains, but it has been possible to recover more of this part of the book through new joins and identifications.

(a) Of the fragments housed in $\mathrm{B}$ frame $5, \mathrm{~d}$ joins $\mathrm{k}$ and $\mathrm{h}$ joins $0{ }^{27}$ Here are revised texts of these pieces (edited by Pietersma on pp. 222-3 and 228-9):

$5 \mathrm{~d}+\mathrm{k}$

$\downarrow$

$$
\downarrow
$$

$4,6 *$ post Pietersma $\quad 6 \overline{\alpha v}[$

]$\varepsilon v \varepsilon \tau[$

$\alpha[\ldots], v \varepsilon$. [
Plate VIII (top)

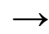

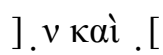

] $\dot{\alpha} \pi \varepsilon \dot{\varepsilon} \theta \alpha \underline{[}[$

Airví $\pi \tau$ ov oi $\mu \varepsilon \gamma 1 \sigma \tau[\hat{\alpha} v \varepsilon \varsigma$

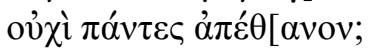

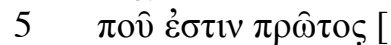

$\tau \alpha \tau \circ \varsigma \dot{\alpha} v[\theta(\rho \omega ́) \pi \omega v$

5

í] $\psi \eta \lambda \operatorname{có}_{\alpha \alpha \tau o \varsigma} \dot{\alpha} v \theta(\rho \omega ́) \pi \omega[v$

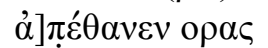

]vท̣ं

]. . [

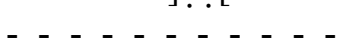

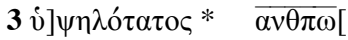

$\downarrow$

'of Egypt the chiefs ... Didn't they all die? ... Where is first (?) ... - est of men ...'

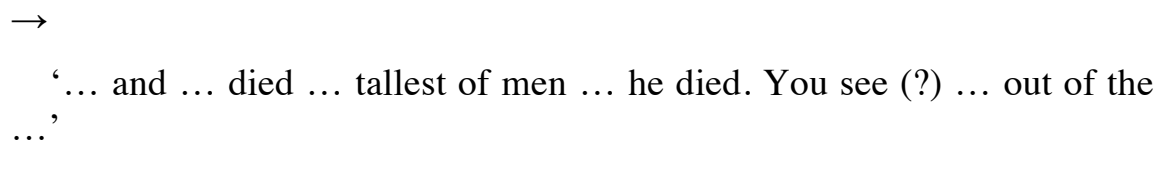

${ }^{27}$ Pietersma's tentative placing of $\mathrm{k}$ alongside the lower part of $\mathrm{h}(227)$ is now seen to be incorrect. There is an apparent blank space above $5 \mathrm{~d} \rightarrow 1(5 \mathrm{~d}+\mathrm{k} \rightarrow 3)$, and Pietersma (228) takes it to represent the upper margin, but it is due to surface loss: comparison with the other side shows (and the new join confirms) that this is not the top of the written area. 
$\downarrow$

$4 \pi \alpha ́ v \tau \varepsilon \varsigma$. Pietersma transcribes $\eta \alpha \mu \pi \varepsilon$ in the left-hand piece (d), but $\pi \alpha \nu \tau \varepsilon$ seems clear. Of $\pi$, we have traces of both uprights and a suggestion of the crossbar at letter-top level; the uprights do not continue upwards past the crossbar. $v$ is formed like that in the next line; then the letter before $\varepsilon$ has only one upright, and $\pi$ seems excluded.

$6 \tau \alpha \tau \circ \varsigma_{\alpha} v[\theta(\rho \omega ́) \pi \omega v$. The pattern 'the most ... of men' (to be followed by 'didn't even he die?', cf. on $5 \mathrm{~h}+\mathrm{o} \rightarrow 3$ below) seems characteristic of the section. Cf. $\rightarrow 3,5 \mathrm{~h}+\mathrm{o} \downarrow 7$, V fr. D.2 (both edited below).

$7 \alpha[\ldots] . v \varepsilon$.[. Pietersma transcribes $\alpha[\ldots] v \varepsilon[$ [. The identification of the additional traces is uncertain. The traces shown as ]. suggest an upright with an oblique descending from left to right attached on the right and a further high trace above it. . [ is a low trace. $\dot{\alpha}\left[\pi \varepsilon^{\prime} \theta\right] \alpha v \varepsilon \varphi$ is an obvious guess in the context, but it is not easy to read $\alpha$ before $v$.

$2,4 \mathrm{Cf}$. on $5 \mathrm{~h}+\mathrm{o} \rightarrow 3$ below.

3 vं] $\psi \eta \lambda$ ó $\alpha \tau$ oc. Pietersma read $\psi \eta \lambda$ oyo in the left-hand fragment $(\mathrm{k})$, but the reading is not in doubt: the crossbar of the $\tau$ continues to the left of its upright, and the following $\alpha$ resembles the first in the line below.

$5 h+o$

$\downarrow$

]v viòv [

] $\dot{\alpha} v \theta(\rho \omega ́) \pi \omega[v$

]...[

]. [

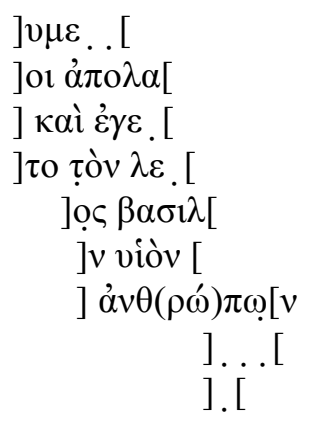

$\downarrow$

$7] \overline{\alpha v \theta \pi \omega}[\quad *$
Plate VIII (middle)

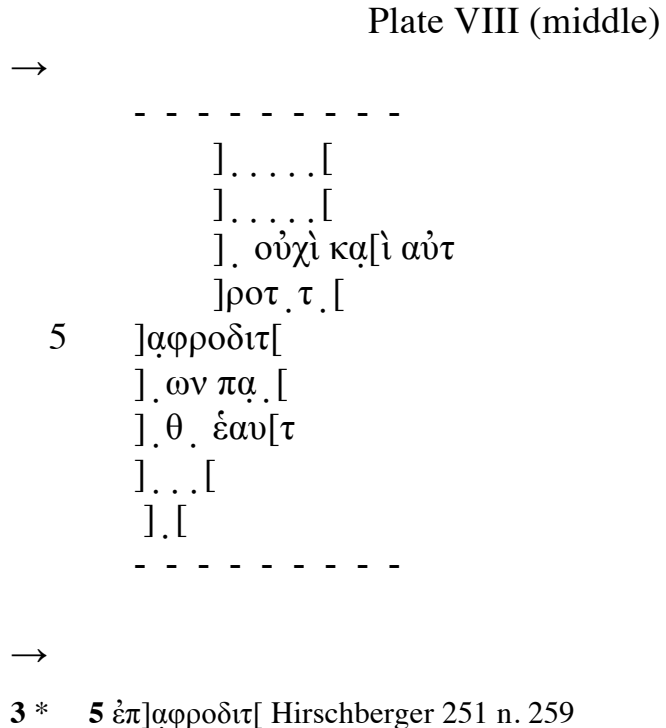


$\downarrow$

'... king $\ldots$ son $\ldots$ of men ...'

$\rightarrow$ ‘.. Didn't even ... - self ...'

1 ] $v \mu \varepsilon$. . [. The epsilon is now clear following the join ( $\mu_{\mu \alpha}$. Pietersma). After it, the lower parts of two letters ( $\lambda \eta \underline{\text { Pietersma) }}$.

$2 \dot{\alpha} \pi \circ \lambda \alpha[$. The final alpha is like that in line 7: Pietersma's $\varepsilon$ seems excluded.

$3 \dot{\varepsilon} \gamma \varepsilon$. [. Of the final letter, only a speck on the line ( $v[$ Pietersma).

$4 \lambda \varepsilon$. [. The last trace is an upright: Pietersma's $\gamma$ is a possible reading.

5 ]ọ. Pietersma has ].o, but the sigma is clear and unambiguous, matching that in $5 \mathrm{~d}+\mathrm{k} \downarrow 6$ (above). Of the preceding letter, only the edge of an arc is preserved.

1-2 The surface is rubbed in both the joined pieces, and it does not seem worthwhile to attempt a decipherment.

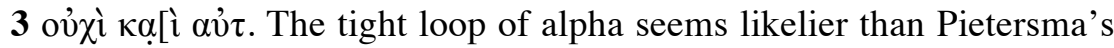
$\mathrm{o}$ at the end. 'Didn't even he/she/they too die?' appears to have occurred repeatedly in this section, to judge by Eth: for Greek examples, cf. $5 \mathrm{e}+\mathrm{g} \downarrow 4,6-7,8-9$ (edited in (b) below), 5deghk $\rightarrow 23-4$ (Pietersma's

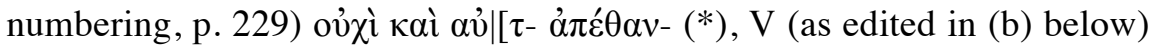
frr. C.9 (with n.), 11, D.3, 5, 8, and perhaps B $5 \mathrm{~d}+\mathrm{k} \rightarrow 2$ and 4 (above) and $6 \mathrm{e} \rightarrow 3-4$ (p. 240 Pietersma $^{28}$ ), where only the verb is preserved. Cf. also

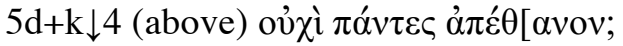

(b) V frr. C and D, hitherto unplaced, turn out to belong to this section of the book. Fr. C overlaps B $5 \mathrm{e}+\mathrm{g} \downarrow$, and fr. D contains material familiar from B, with '- est of men' (2) and the refrain 'didn't even he/she/they die?' $(3,5,8)$ : cf. on these expressions above on B $5 \mathrm{~d}+\mathrm{k} \downarrow 6$ and $5 \mathrm{~h}+\mathrm{o} \rightarrow 3$. These two fragments thus belong much later than frr. A and B, but close

\footnotetext{
${ }^{28}$ Pietersma places this fragment in lines $13-18$ in his reconstruction on the facing page, but its original level is unknown: cf. Pietersma 235.
} 
to each other. ${ }^{29}$ Here are revised editions, preceded by a revised edition of B $5 \mathrm{e}+\mathrm{g} \downarrow$, corresponding to lines 20-29 of Pietersma's composite 5deghk $\downarrow$ (p. 223); upper half-brackets mark the contribution of the other papyrus.

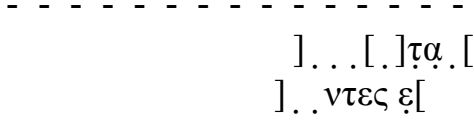

]. $\beta$ г $\alpha \sigma^{\urcorner} \imath\ulcorner\lambda \hat{\imath} \varsigma \tau \hat{\eta}\urcorner \varsigma A[\imath \gamma v ́ \pi \tau o v$

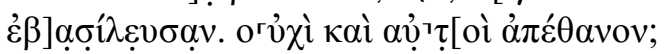

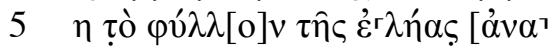

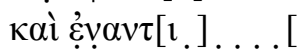

$\dot{\alpha} \pi \dot{\varepsilon} \theta \alpha v \varepsilon v$. [] ] $\pi \mathrm{ov} \varepsilon[$

$\alpha . \tau \eta[.] \varepsilon v \alpha[.] . . \varepsilon v[$

$10 \tau[$

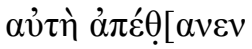

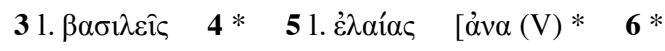

'... kings of [Egypt] ... reigned. Didn't even they [die?] ... the leaf of the olive ... and facing ... died. Where ... [even] she died ...'

3 ]. is an upright: the choices include o]! and $\kappa \alpha]$ í.

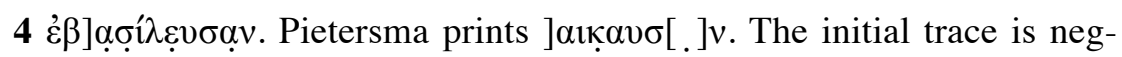

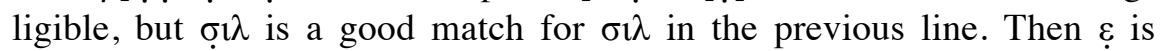
missing its top, but the letter is otherwise similar to the first $\varepsilon$ of $5 \mathrm{~d}+\mathrm{k} \downarrow 2$ (edited above). The $\alpha$ to the right of $\sigma$ is no more than a spot on the edge.

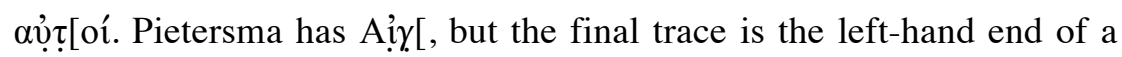
high crossbar with blank space to the left: gamma seems excluded.

6-7, 8-9 Perhaps further examples of the refrain 'Didn't even he/she/

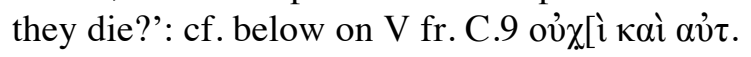

\footnotetext{
${ }^{29}$ The text on the other side of the roll gives no clues to their position: cf. J.-P. Mahé, Fragments hermétiques dans les Papyri Vindobonenses Graecae 29456 r $^{\circ}$ et $29828 \mathrm{r}^{\circ}$, in E. Lucchesi and H.D. Saffrey (edd.), Mémorial André-Jean Festugière: Antiquité païenne et chrétienne (Cahiers d'Orientalisme 10; 1984) 51-64 at 55.
} 
6 है $y \alpha v \tau[$ [. Pietersma gives $\dot{y} \varphi \alpha v \tau[$. Of $\varepsilon$, we have the upper part of a curve, resembling the top of the first epsilon in line 8; then of $v$, there is the curve formed by the junction of the oblique and the second upright.

$7 \pi$ ov $\varepsilon$ [. The final $\varepsilon$ leans precipitously forward, like the second in this line, and lacks the turn-up, like the first in the next line and that in line 5. The lower of the strokes on the right is too flat to represent the lower branch of kappa, which Pietersma reads here. $\pi$ ov will then have been followed by $\hat{\varepsilon}[\sigma \tau \imath v$, as in $5 \mathrm{~d}+\mathrm{k} \downarrow 5$ (edited above), or $\varepsilon[\imath \sigma \mathrm{l}$, as in $6 \mathrm{a}+\downarrow 15$ (p. 233 Pietersma): Eth shows that such phrases occurred repeatedly in this section.

$8 \alpha$. $ๆ[$.]. Pietersma gives $\alpha v i \eta$, which may be correct. There appears to be a short gap to the right, but it may not have held a letter.

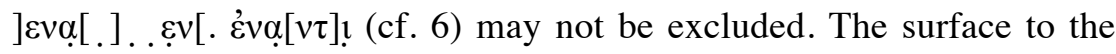
left of $v[$ is rubbed.

V fr. C

].. [

]$\xi \alpha, ![$

]....... [

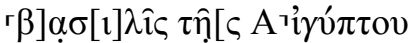

5

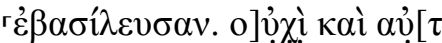

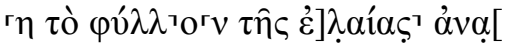

]...... [

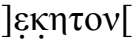

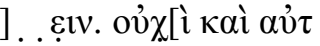

10

]$\alpha \tau \alpha \dot{\alpha} v \alpha[$

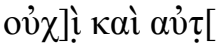

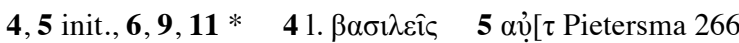

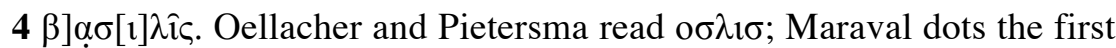
two letters and indicates word-end after them. The surface is abraded at the start and the traces are compatible with the right-hand side of the loop of alpha. Then the top layer has come off to the left of $\lambda \mathrm{k} \varsigma$ and the resulting gap is wide enough to hold an iota. 
$\tau \hat{n}[\varsigma$. The final trace is an upright touching the left-hand end of a crossbar near the top: eta is an acceptable reading.

5 o] ưx. The surface is abraded; I take the initial traces to represent the right-hand side of upsilon, followed by the right-hand side of the junction of chi with ink in place on the left suggesting the left-hand side of the letter. $!$ is an upright on the edge of the gap where the top layer is lost (cf. 4 n.). Pietersma's $̣ ̣ ı$ is closer to the truth than Maraval's ]. $\varepsilon 1$.

$6 \dot{\varepsilon}] \lambda \alpha i^{\prime} \alpha \varsigma$. The final trace is the lower left-hand arc of a circle with damaged surface above and to the right; the preceding alpha is unambiguous and nearly complete except at the extreme left where the upper layer is missing. Maraval read $\grave{\eta}$ in place of $\alpha \varsigma$; Pietersma prints an undotted eta.

$\dot{\alpha} v \alpha \underline{[}$. So Maraval ( $\alpha v \eta$ Pietersma). The curved final trace appears similar to the previous $\alpha$.

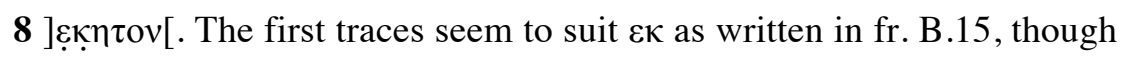
nothing remains of the lower branch of kappa. If the reading is correct,

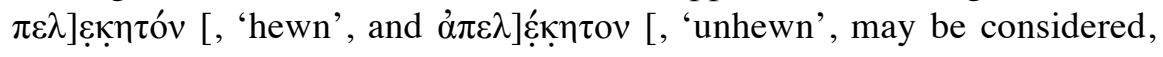
but neither word seems particularly likely in this context.

9 ]. . $\varepsilon ı v$. Perhaps an infinitive. Nu is broad, with curves at the junctions of the strokes, as in line 10, and has a narrow blank space to its right at the

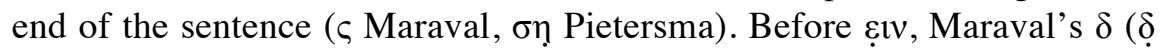
Pietersma) seems possible; chi and lambda would be flatter than expected but are perhaps not ruled out. At the start, there is a low cross-stroke joining the ascending oblique of the second letter.

ov $\chi[$ í. The last trace (Pietersma's $\lambda$ ) is comparable to the left-hand side of the $\chi$ in fr. B.8.

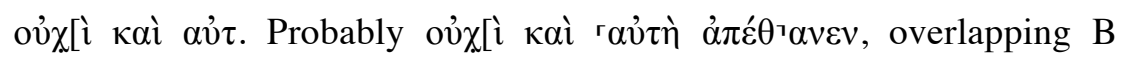
$5 \mathrm{e}+\mathrm{g} \downarrow 9$.

11 oủ $\chi$ lí. ]! is a trace at letter-top level on the edge. 
V fr. D

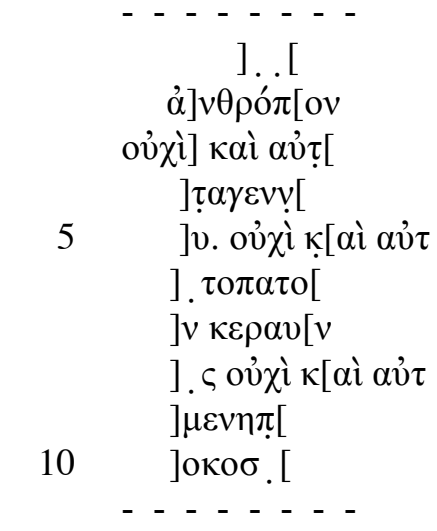

$\mathbf{2 , 3}, \mathbf{5}, \mathbf{8} * \quad$ 2 1. $\dot{\alpha} v \theta \rho \omega ́ \pi \omega v \quad 7$ Pietersma 266

'... of men ... [Didn't] even ... Didn't [even] ... thunderbolt ... Didn't [even] ...'

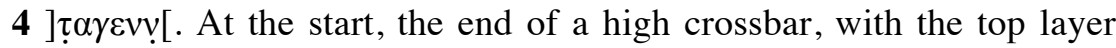
missing below. $v[$ is an upside-down $v$-shape on the edge like the left-hand side of the nu in line 2. Maraval's $\alpha[$ seems unsuitable: there is no loop.

$5 \kappa[\alpha i$. Of $\kappa[$, remains of an upright hooked to the left at the top, resembling that of the kappa in fr. C.5.

$7 \kappa \varepsilon \rho \alpha v[v$. It is not clear how the appearance of a thunderbolt here is to be explained. Erho notes that one possibility is a simile, e.g. 'Where is such-and-such, who ran faster than a thunderbolt?'

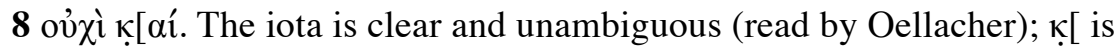
an upright with a stroke emerging from it low on the right, suggesting kappa written as in line 10. Maraval, followed by Pietersma, has $\chi \rho \eta$ [ at the end, but the upright following chi seems short for rho and has no loop, while the crossbar of eta would be expected to be higher.

II.iii. With the information now available, some progress can be made in reconstructing the first part of the book.

$\mathrm{O} \downarrow$, p. 25 of a codex, overlaps at the start (1-8) B $5 \mathrm{a}+\downarrow 12-16$ (p. 205 Pietersma). A line of O holds about 20 letters, and each page has 18 lines. The first 24 pages will thus have held about $8640(20 \times 18 \times 24)$ letters. O 
has a fuller version of the conversation that it contains than $\mathrm{B}$, but the figure still helps to determine the number of pages preceding B $5 \mathrm{a}+\downarrow$. The quantity of text given by each leaf is fairly constant in the earlier part of B, so far as we can tell, though more is squeezed into later leaves. If we assume that a line held on average 28 letters and a page 25 lines (cf. the reconstructed pages $A b, B a$, and $B b, \S$ II.i above), a page will have held on average about 700 letters, and 8640 letters would take up rather more than twelve average pages. Pietersma argued plausibly that 'the extant pages belong to a single quire or gathering of papyrus sheets, which had the somewhat unusual page order of $\rightarrow \downarrow$ till the centre and $\downarrow \rightarrow$ thereafter' (77). With this in mind, we may now try to identify the contents and order of the opening pages. In what follows, I do not attempt to give a complete account of the plot, but mention only a selection of salient points.

The opening of the work is preserved at the top of $1 \mathrm{abcd} 3 \mathrm{~h} 4 \mathrm{c} \rightarrow(\mathrm{pp} .97$ and 107 Pietersma),${ }^{30}$ which I take to form a single page. We begin with

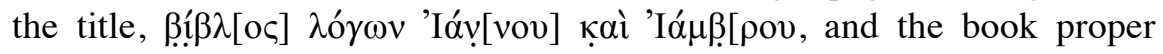

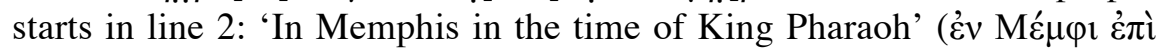
$\left.\beta \alpha \sigma \imath \lambda \varepsilon \omega^{\prime}[\varsigma] \Phi \alpha \rho \alpha \omega\right)$. Line 3 gives us the subject, a 'beautiful young wom-

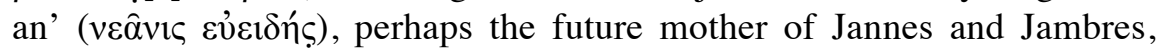
who plays an important part in the book, and line 4 mentions an 'intimate

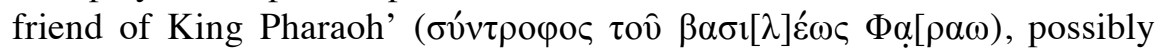
their future father. ${ }^{31}$ Their marriage and the birth of their sons may have been narrated briefly; then in the lower part of the page, we have what appears to be the mother's prophetic dream, and the narrative continues on the $\downarrow$ side (pp. 103 and 113 Pietersma) with Jannes' reaction. The transition from the foot of $\rightarrow$ to the top of $\downarrow$ seems natural enough: there are anatomical references in both places. There is no reason, then, to find more than one leaf here. Rather, we have one leaf of the expected height, about $27 \mathrm{~cm}$ (cf. above on leaves $A$ and $B$ ), with the $\rightarrow$ side holding 25 lines and the $\downarrow$ side $24 .{ }^{32}$

\footnotetext{
${ }^{30}$ Pietersma supplies several letters to the left of $1 \mathrm{ab} \rightarrow$, but this arrangement is to be rejected on physical grounds. Damage to the codex has given 1 ab the same shape as the top inner corners of leaves $A$ and $B$ (partially edited above, $\S$ II.i), an L on its side, and it must like them be located so as to give line-beginnings on the $\rightarrow$ page.

${ }^{31}$ Pietersma (98; cf. id. ap. P.W. van der Horst, JSJ 25 (1994) 329) would emend to

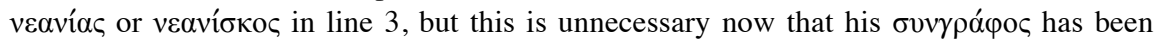
eliminated from line 4: for the reading there, see Henry 59.

${ }^{32}$ P.Mich. inv. 4925 v. (editions: Schmelz 1202-7; Hirschberger 230-31), a genealogical fragment mentioning Jannes (7, 9-10) and apparently Jambres ([8, 10]), has been assigned to the early part of the book, but there is no room for text corresponding to that of
} 
Next we may place the leaves that I have called $A$ and $B$, three of whose four pages are edited above. The first of the four, $A a$ (Pietersma's frame 4abdefi $\rightarrow$, p. 175), has at its top a speech addressed to more than one person and possibly referring to waking from sleep (1 $\dot{\varepsilon} \xi 0 \pi[)$; Jambres appears in line 3. The speaker may be the father of Jannes and Jambres addressing his sons: he was introduced as the subject in the last line of the first leaf $(1 \mathrm{c}+\downarrow 19) \cdot{ }^{33}$ There follows ${ }^{34}$ a speech of Jannes in which reference is made to the three years that he is to spend in the service of the king (V fr. A.2-3, cf. B Ab14-16), after which, in the light of his mother's dream, he expects to die. ${ }^{35}$ Jannes makes his way to Memphis and challenges Moses and Aaron until the time of his death draws near (Ba19-20); then he withdraws. At the foot of $B b$, we find him in conversation with Jambres, noting that sinners have little time left to live, and I have suggested $(B b 12-27 \mathrm{n}$.) that he continued by noting that he too would soon be punished for opposing the power of God.

The leaf whose lower part is given by 2 a may have followed. On its $\rightarrow$ side (p. 137 Pietersma) we have an earthquake and thunder (10-11), which causes Jannes to run to his library (14-15). This may be a prelude to the appearance of emissaries on the $\downarrow$ side (p. 145 Pietersma). The visitors have been sent by the Lord to take Jannes away to death (7-10). But

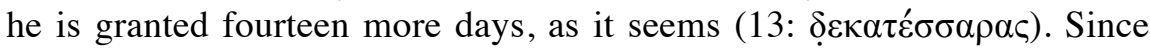
Jannes can still say vaguely at $A b 12$ 'whenever the time of my death comes', and a period of fourteen days remaining to him is never mentioned in the long stretch of leaves $A$ and $B$ known to us, this page seems likely to come later in the book, after his death has drawn near.

One more leaf remains to be placed in the narrative part of the book preceding the scene of necromancy, that to which $2 \mathrm{~h}$ and $3 \mathrm{~g}$ belong (pp. 191 and 199 Pietersma), now supplemented by H. 2h, with the upper left-hand corner of a page on the $\downarrow$ side, has the same shape as $5 \mathrm{~b}$, the top inner corner of the leaf composed of 5abcfp (pp. 205 and 213 Pietersma);

this fragment on the first page of B as now constituted. One could, as Erho remarks, think of a different recension, but references to Jannes and Jambres come up in works of various kinds (cf. e.g. Pietersma 24-35), and the context of the Michigan fragment is unknown.

${ }^{33}$ Cf. Henry 59-60 for the text.

${ }^{34} \mathrm{Cf}$. on the text of this page Henry 63-6.

${ }^{35}$ Pietersma's text has allusions to illness at the top of the page, but they seem doubtful.

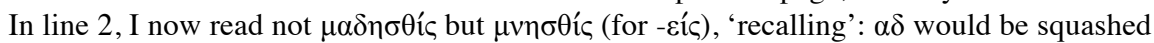
and is not easy to reconcile with the traces. Then the sequence ] $\varepsilon v 0 \sigma \varepsilon ![$ in line 4, which

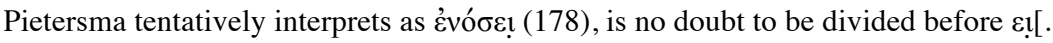


5 b too has the upper left-hand corner of a page on the $\downarrow$ side. $\downarrow$ must then precede $\rightarrow$ in this leaf on physical grounds. ${ }^{36}$ At the top of the $\downarrow$ page, Jannes expresses his anguish: 'my soul is perishing and ... my whole body is in turmoil ${ }^{9}{ }^{37}$ The $\rightarrow$ page narrates the destruction of the king and his army in the Red Sea, and a reaction to these events follows at the top of 5 abcfp $\downarrow$.

So far, we have five leaves where the evidence of $\mathrm{O}$ would lead us to expect six. But the preserved page-top of $2 \mathrm{~h} 3 \mathrm{~g} \downarrow$ cannot follow immediately on the preserved page-foot of $2 \mathrm{a} \downarrow$ (nor indeed on that of $2 \mathrm{a} \rightarrow$, if the sequence in that leaf were to be reversed). We may then suppose that a leaf has been lost between $2 \mathrm{a} \downarrow$ and $2 \mathrm{~h} 3 \mathrm{~g} \downarrow$. If the sequence of that leaf was still $\rightarrow \downarrow$ and $2 \mathrm{~h} 3 \mathrm{~g}$ was the first leaf with the order $\downarrow \rightarrow$, we could have a codex consisting of five bifolia: $1 \mathrm{a}+, A, B, 2 \mathrm{a}+$, and the lost leaf, each with the order $\rightarrow \downarrow$, will have been followed by $2 \mathrm{~h} 3 \mathrm{~g}+, 5 \mathrm{a}+$, and three more leaves, each with the order $\downarrow \rightarrow$. Three leaves will easily accommodate the material of Pietersma's 5d+ (pp. 223 and 229), 6a+ (pp. 233 and 241), and $7 \mathrm{a}+$ (pp. 247 and 255). It is not easy to establish the original order of this material (cf. Pietersma 224-7).$^{38}$ Eth is of limited value in this respect, but it does at least present no obstacle to the proposed reconstruction: for a full discussion, see the introduction to the second leaf in $\S$ I above.

\footnotetext{
${ }^{36}$ Erho had already preferred this sequence on grounds of content. Pietersma 192 considers a physical argument for the sequence $\downarrow \rightarrow$, which he deems 'unlikely though not impossible in view of the contents', but does not mention $5 \mathrm{~b}$ in this connection. The order of the pages will be the same in $\mathrm{H}$.

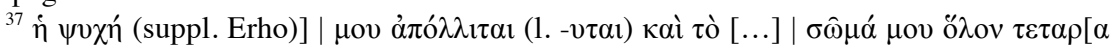

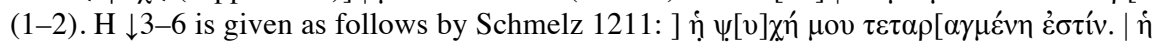

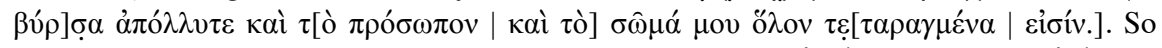

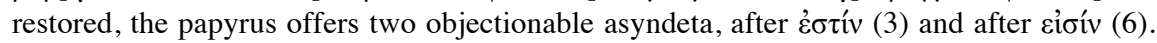
But the reading at the start of line 4 is incorrect: the papyrus has not ] $\sigma \alpha$ but ] cot. The tail $^{\circ}$ of the alpha is raised to join the iota at the top, and there are clear traces of the iota itself, while at the start, we have the branches of kappa, written as in $\rightarrow 9$, with the lower extending further to the right than the upper; sigma is quite unsuitable. We may then

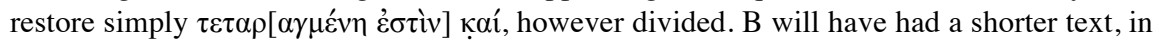
which the perfect passive of $\tau \alpha \rho \alpha ́ \sigma \sigma \omega$ was used only once. (Other supposed disagreements

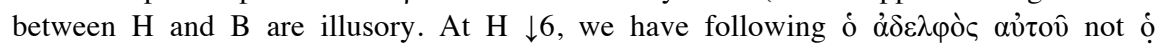

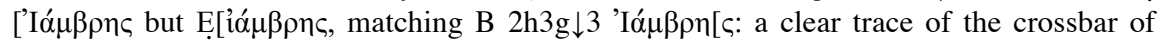
epsilon is preserved on the edge. On $\mathrm{H} \rightarrow 8$, see above on $\mathrm{B} A b 4)$.

${ }^{38}$ The third leaf from the end will have included $3 q$ (pp. 150 and 166 Pietersma), a small fragment attached to the inner edge of the leaf here called $B$, near the foot; but this does not seem to help in narrowing down the possibilities.
} 


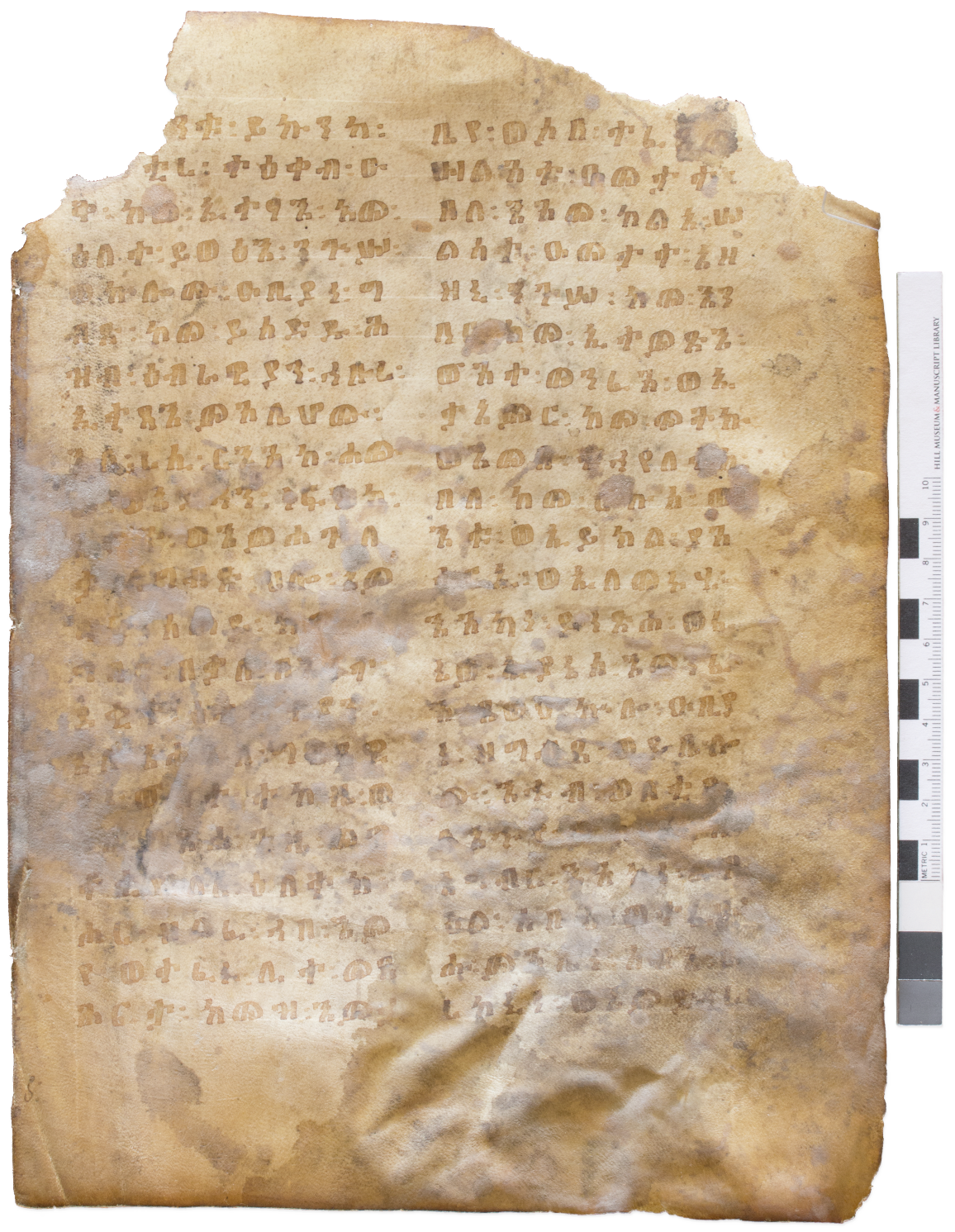

Plate I

Schneider ms. frag. 19, f. 1r

Image by T. Erho and L. Stuckenbruck 


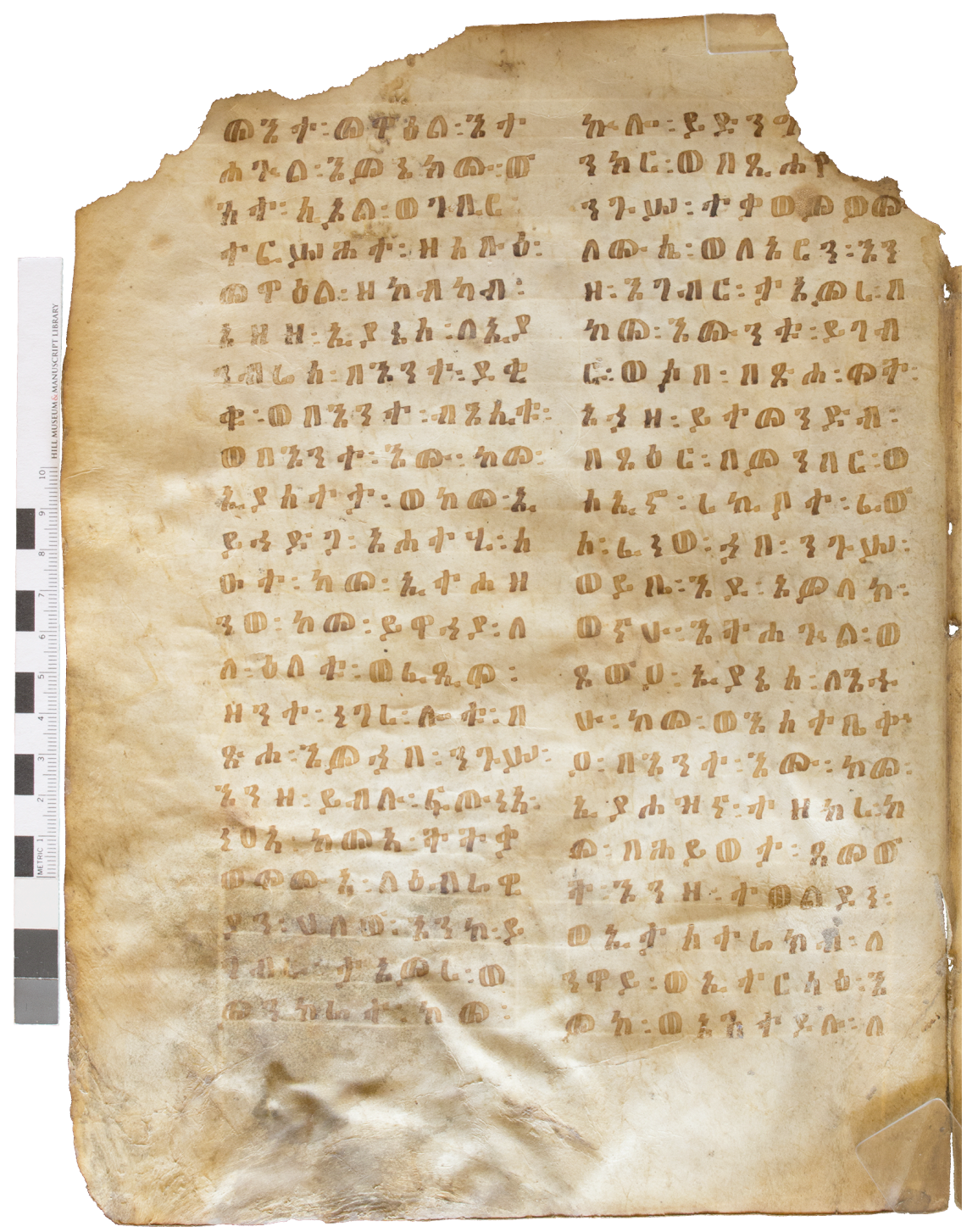

Plate II

Schneider ms. frag. 19, f. 1v

Image by T. Erho and L. Stuckenbruck 


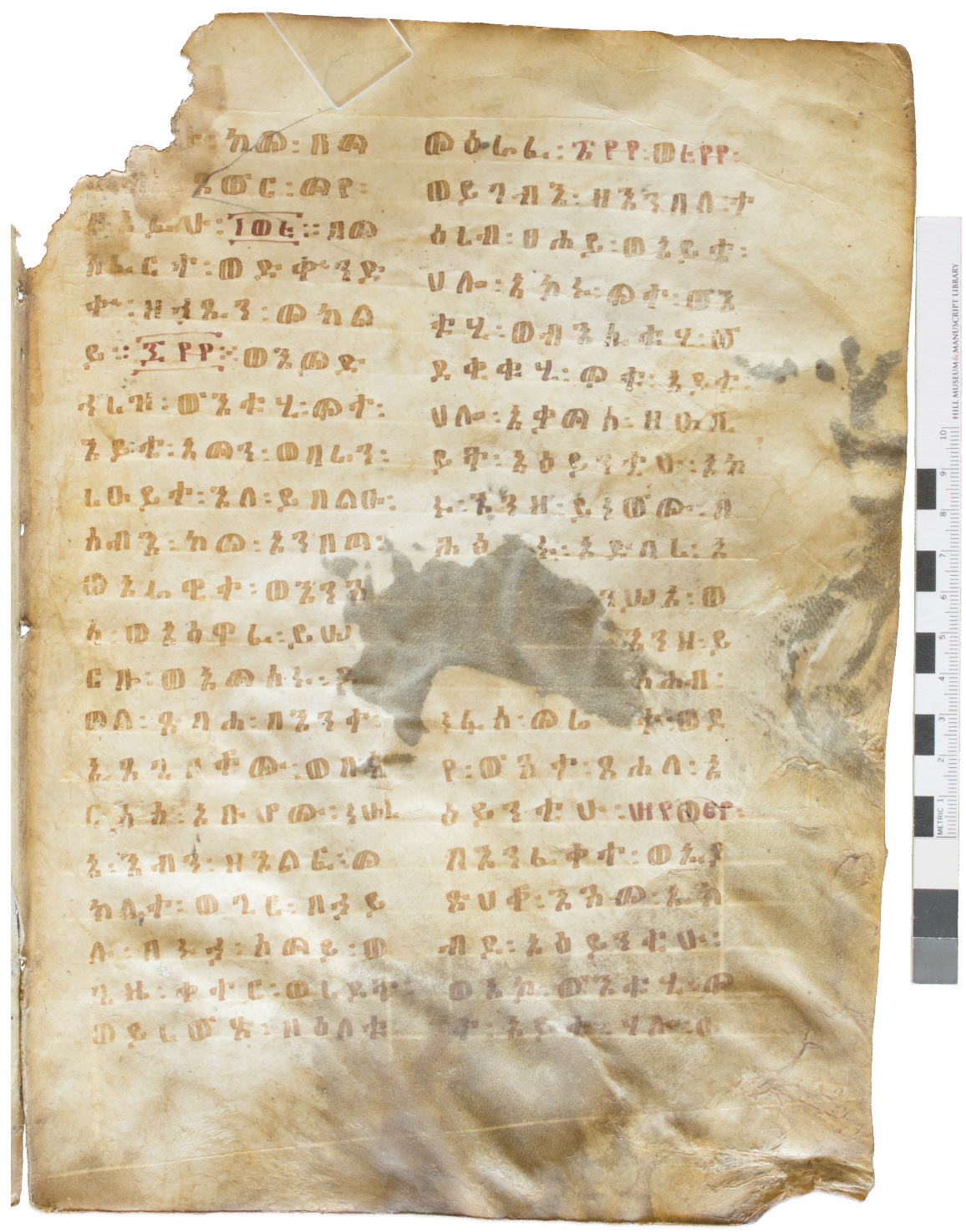

Plate III

Schneider ms. frag. 19, f. 2 r

Image by T. Erho and L. Stuckenbruck 
T.M. Erho \& W.B. Henry, The Ethiopic Jannes \& Jambres \& the Greek Original 219

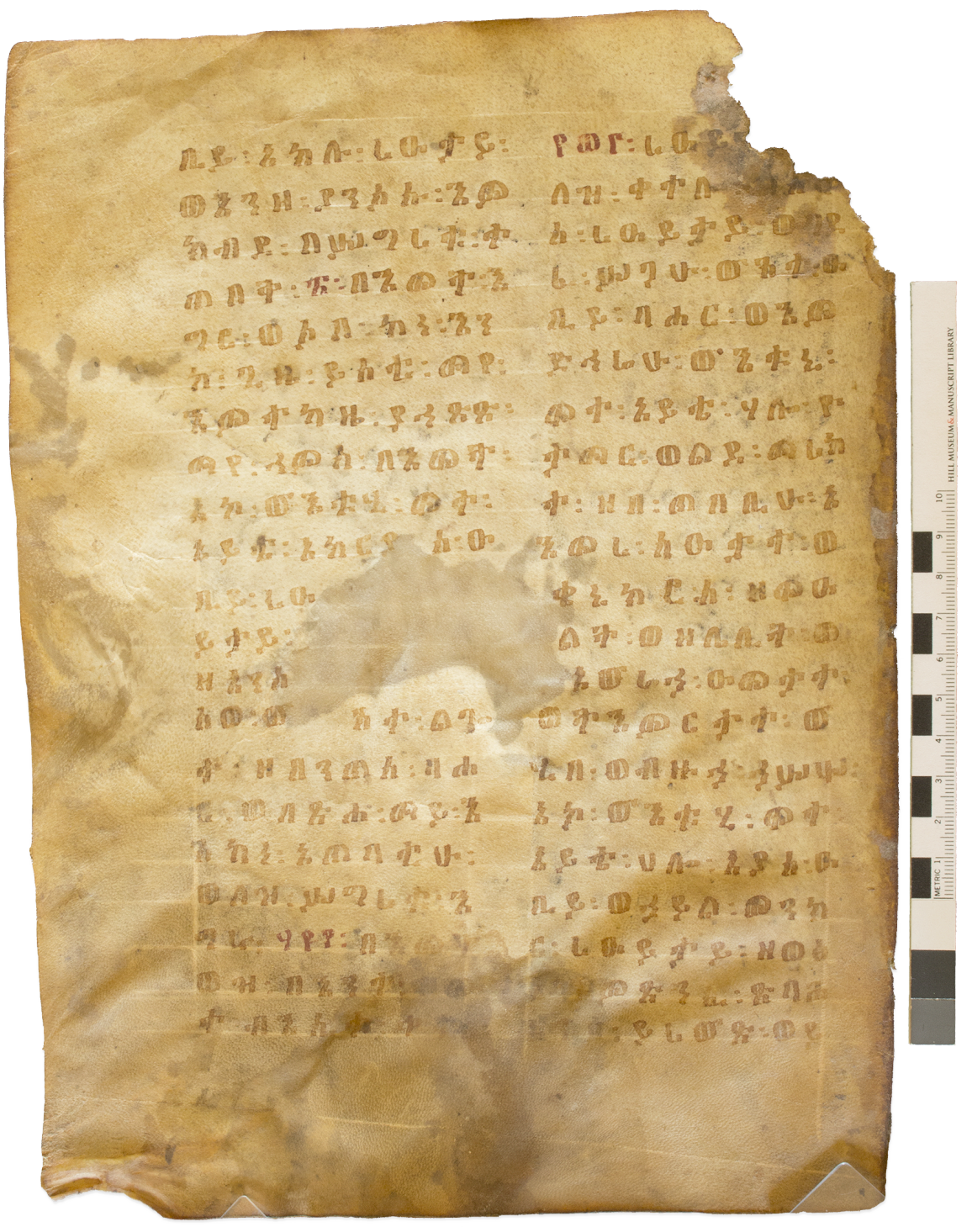

Plate IV

Schneider ms. frag. 19, f. $2 \mathrm{v}$

Image by T. Erho and L. Stuckenbruck 

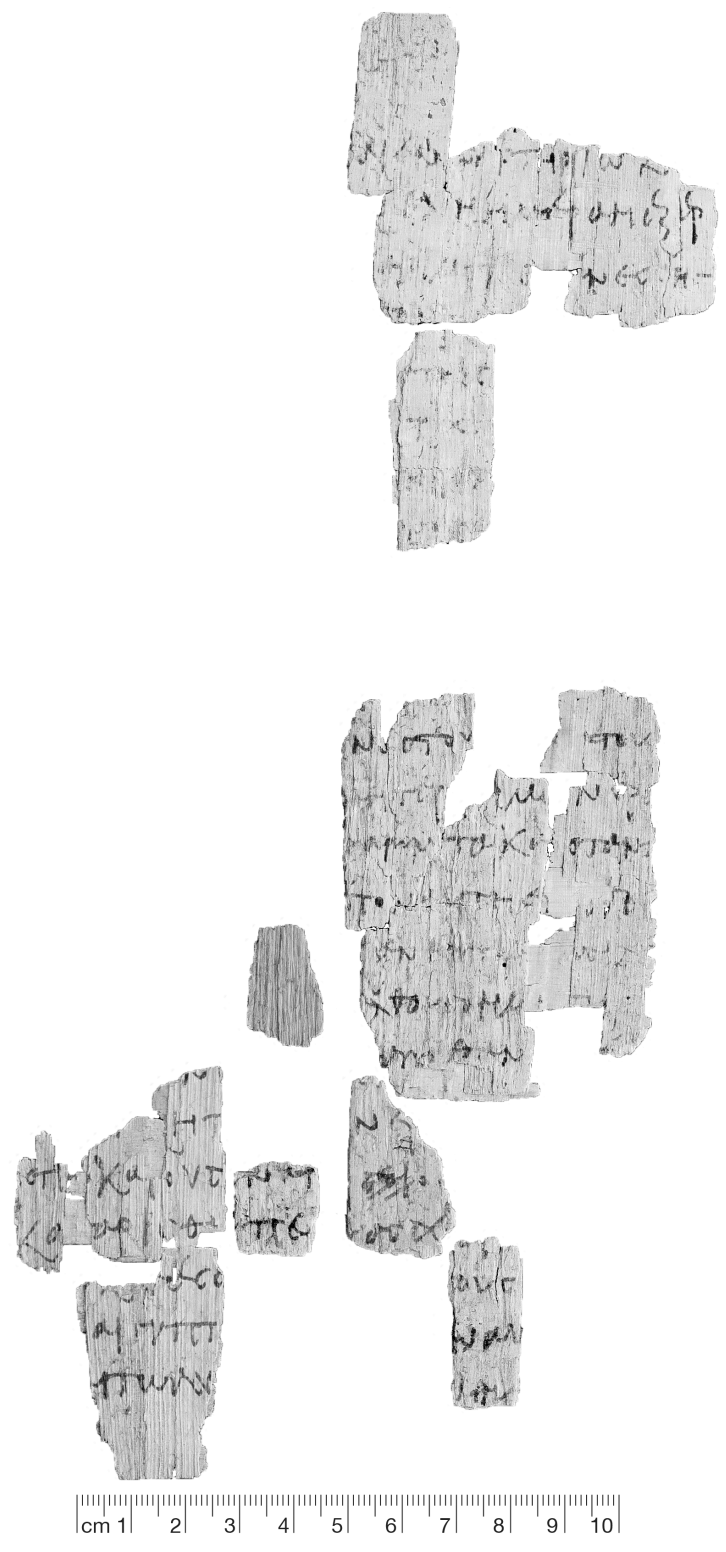

Plate V

P.Chester Beatty CBL BP XVI $A b$ (montage: W.B. Henry)

The Center for the Study of New Testament Manuscripts (www.csntm.org) digitized CBL BP XVI at the Chester Beatty Library, Dublin. 
T.M. Erho \& W.B. Henry, The Ethiopic Jannes \& Jambres \& the Greek Original 221
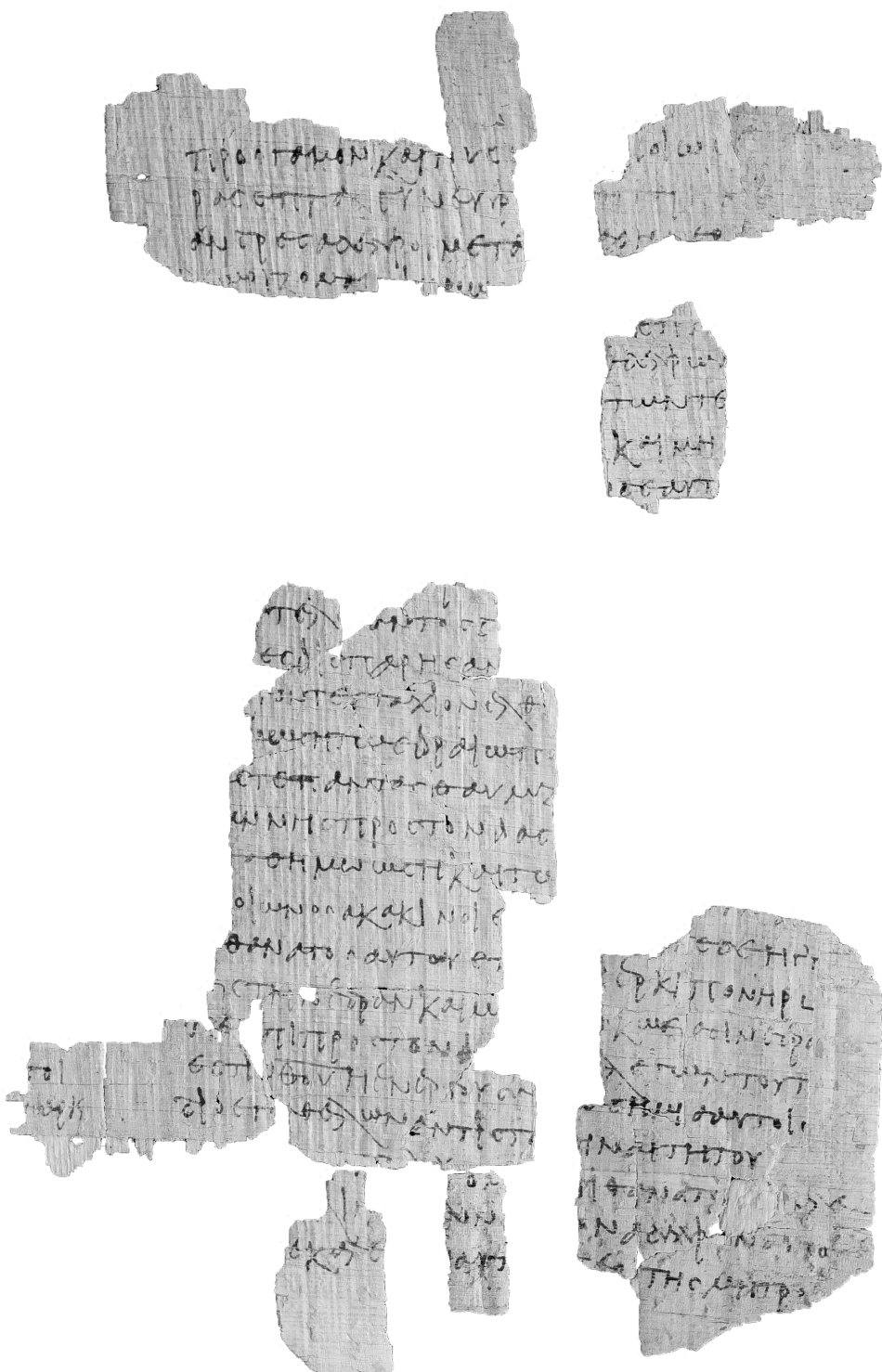

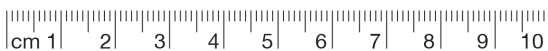

Plate VI

P.Chester Beatty CBL BP XVI $B a$ (montage: W.B. Henry)

The Center for the Study of New Testament Manuscripts (www.csntm.org) digitized CBL BP XVI at the Chester Beatty Library, Dublin. 

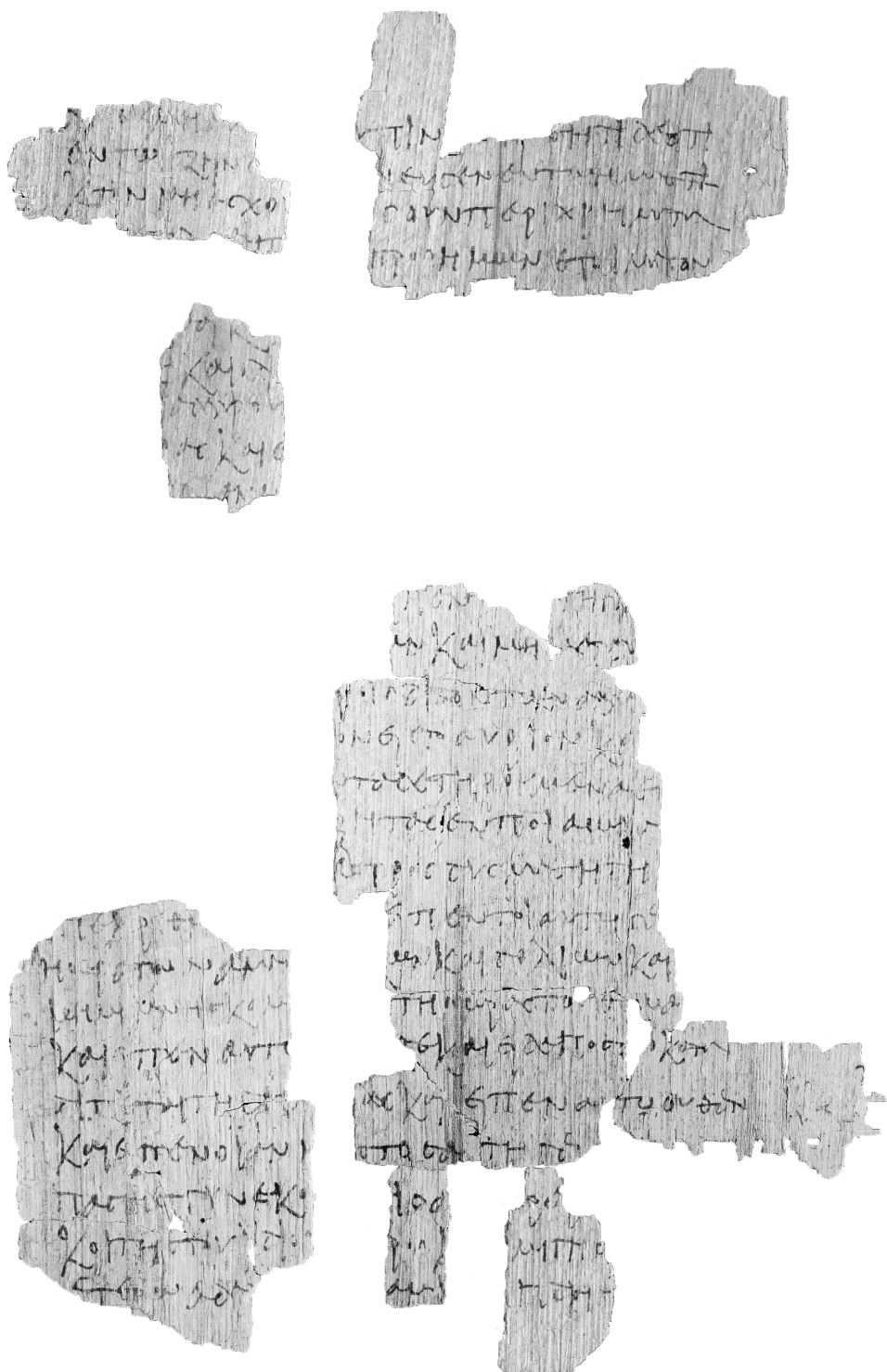

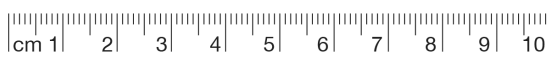

Plate VII

P.Chester Beatty CBL BP XVI $B b$ (montage: W.B. Henry)

The Center for the Study of New Testament Manuscripts (www.csntm.org) digitized CBL BP XVI at the Chester Beatty Library, Dublin. 
T.M. Erho \& W.B. Henry, The Ethiopic Jannes \& Jambres \& the Greek Original 223
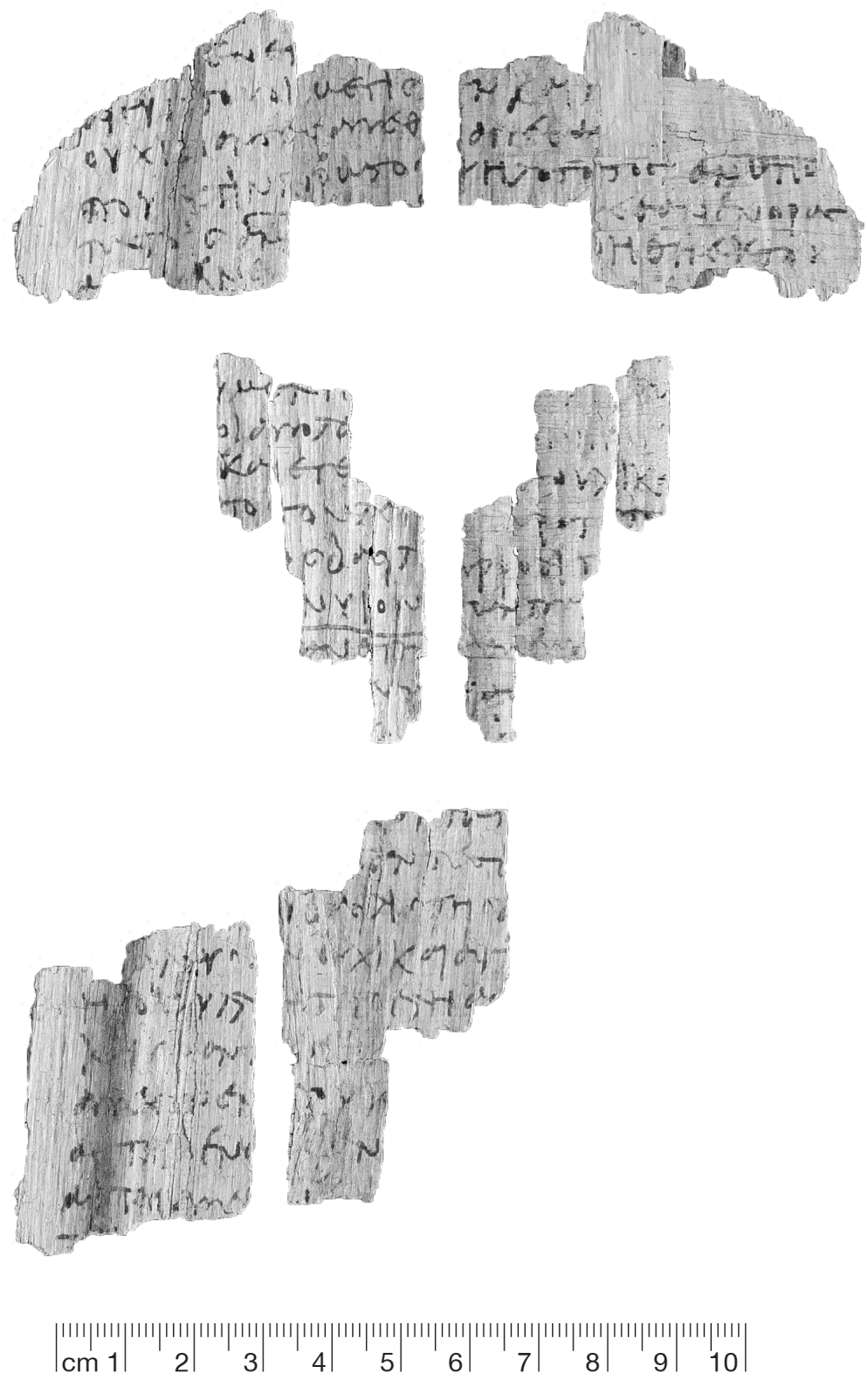

Plate VIII

P.Chester Beatty CBL BP XVI $5 \mathrm{~d}+\mathrm{k} \downarrow$ and $\rightarrow, \mathrm{h}+\mathrm{o} \downarrow$ and $\rightarrow, \mathrm{e}+\mathrm{g} \downarrow$ (montage: W.B. Henry) The Center for the Study of New Testament Manuscripts (www.csntm.org) digitized CBL BP XVI at the Chester Beatty Library, Dublin. 